\title{
Model-assisted analysis of fluidized bed chemical-looping reactors
}

\author{
Zhiquan Zhou, Lu Han, George M. Bollas* \\ Department of Chemical \& Biomolecular Engineering, University of Connecticut, Storrs, 191 \\ Auditorium Road, Unit 3222, Storrs, CT 06269, USA. *Corresponding Author: Tel: +1-860-486- \\ 4602. Email: george.bollas@uconn.edu;
}

\begin{abstract}
A three-phase hydrodynamic model is employed for the analysis of experimental data of chemical-looping reduction with nickel-based oxygen carriers and methane as the fuel. The model rigorously accounts for the mass, energy, and pressure balances, and the effect of oxygen carrier entrainment in the freeboard region. Model predictions are in good agreement with the relevant experimental data. The capability of the model to be used in the scale-up of fixed-bed kinetic studies of oxygen carriers to fluidized bed pilot-scale reactors is illustrated. The generality and validity of the model are analyzed, so that it can be used for further reactor design studies. In particular, sensitivity analyses, in terms of the crucial hydrodynamic parameters and correlations are carried out and the effects of important parameters, such as bubble size, mass transfer, oxygen carrier entrainment and reactions in the freeboard, on the performance of the chemical-looping reducer are investigated.
\end{abstract}

Keywords: chemical-looping, $\mathrm{CO}_{2}$ capture, bubbling bed fluidization, reactor design, simulation. 


\section{Introduction}

Chemical-looping combustion (CLC) has emerged as a promising process for fuel combustion with low-cost $\mathrm{CO}_{2}$ separation and $\mathrm{NO}_{\mathrm{x}}$ pollution control. CLC takes advantage of the redox behavior of certain metal oxides (oxygen carriers, OC) to seize oxygen in an Oxidizer reactor, which is used thereafter to oxidize a fuel in a separate reactor, the Reducer. Solids circulation between the two reactors is typically accomplished with interconnected fluidized bed configurations, including riser and bubbling fluidized beds (Lyngfelt et al., 2001), two bubbling fluidized beds (Adánez et al., 2006) and dual circulating fluidized bed reactors (Pröll et al., 2009). Alternative reactor concepts for CLC include alternating flow fixed-bed reactors (Noorman et al., 2010), moving bed reactors (Fan et al., 2008), and rotating fixed-bed reactors (Håkonsen and Blom, 2011; Zhao et al., 2013). Compared with fixed-bed reactors, fluidized bed reactors are more suitable to process large inventories of solids with small pressure drop and uniform temperature profiles (Zhou et al., 2014a). Bubbling fluidized bed reactors are the most common implementation of lab- and pilot- scale CLC Reducers (Chandel et al., 2009; Gayán et al., 2009; Hoteit et al., 2009; Iliuta et al., 2010; Mattisson et al., 2008; Ryu et al., 2008, 2009). Therefore, most experimental and theoretical work has focused on CLC Reducers operating in the bubbling bed regime, for which pilot-scale experience suggests a smooth transition to the commercial scale, on the basis of well-established scaling-up procedures (Rüdisüli et al., 2012).

In the context of modeling and simulation of CLC Reducers, approaches such as computational fluid dynamics (CFD) and hydrodynamic models have been proposed (Adanez et al., 2012). CFD is capable of representing the detailed hydrodynamic characteristics of the reactor, but it is computationally intensive and has limited applications to process design and sensitivity analysis. Mahalatkar et al. (2011; 2010), Jung and Gamwo (2008), Deng et al. (2009) 
and Wang and coworkers $(2011 ; 2013,2012)$ developed CFD models to simulate the performance of CLC Reducers in bubbling or circulating fluidized beds. Summarizing their results and conclusions, it was observed that fuel conversion can be hindered by large and fast bubbles passing through the reactor and agreement with experimental data depends on the accuracy of the bubble phase modeling.

On the contrary, hydrodynamic modeling approaches (Davidson and Harrison, 1963; Kunii and Levenspiel, 1968a, 1968b; Shiau and Lin, 1993; Tabis and Essekkat, 1992) are more suitable for reactor design and process sensitivity analyses. In the context of simulation of chemicallooping reactors, hydrodynamic models have been often used to provide insights to process efficiency and selectivity. Brown et al. (2010) used the two-phase model by Davidson and Harrison (1963) with the assumptions of bed isothermality and negligible solid carry-over in the bubbles to simulate CLC in a bubbling bed reactor and validated the model against their experimental data. Yazdanpanah et al. $(2011 ; 2014)$ considered the impact of solid in the bubble phase and successfully simulated the experimental results of their $10 \mathrm{~kW}_{\text {th }}$ pilot plant. Iliuta et al. (2010) utilized the Kunii and Levenspiel three phase model (Kunii and Levenspiel, 1968a, 1968b) and successfully predicted their semi-batch CLC reduction reactor data. Their model assumes an isothermal bed and negligible solids entrainment to the freeboard. A similar simulation approach was used by Sahir et al. (2013) for the fuel reactor modeling of chemicallooping with oxygen uncoupling (CLOU). The interconnected fluidized bed reactor model proposed by $\mathrm{Xu}$ et al. (2007) considered a particle population balance with a two-phase hydrodynamic model for the Reducer, assuming perfect solid mixing in the emulsion phase. Similarly, Brahimi end coworkers. (Brahimi et al., 2012; Choi et al., 2012) developed a mathematical model with particle population balance to study the optimal operating range for a 
continuous bubbling bed CLC process. In the analysis by Hofbauer and coworkers (BolhàrNordenkampf et al., 2009; P. Kolbitsch et al., 2009; Philipp Kolbitsch et al., 2009; Kronberger et al., 2003) the presence of a freeboard region was shown to significantly improve fuel conversion (Pröll et al., 2009). Similar findings were presented by Abad et al. (2010), for a steady state CuO-based CLC system. Recently, Peltola et al. (2013a, 2013b) presented a one-dimensional dynamic model of CLC in a dual fluidized bed reactor system focusing the scale-up considerations for CLC.

In this work, a transient hydrodynamic model is developed with the objective to predict and analyze the behavior of CLC bubbling bed Reducers operating with $\mathrm{CH}_{4}$ and supported $\mathrm{NiO}$. The Kunii and Levenspiel $(1969,1968 b)$ three-phase model is used for the simulation of batch CLC reduction experiments. Reaction kinetics, developed previously (Zhou et al., 2014b, 2013) for fixed-bed reactor kinetics analyses, is used for the prediction of bubbling bed Reducers performance, without further fitting. This kinetics model is inclusive of the heterogeneous and catalytic reactions of $\mathrm{CH}_{4}$ and its partial oxidation products, $\mathrm{CO}$ and $\mathrm{H}_{2}$ and thus it allows for an overall analysis of gaseous CLC with Ni oxygen carriers. The reactor energy balance, pressure balance, gas volume change due to reactions and pressure variations, and the effect of oxygen carrier entrainment in the freeboard region are all considered in the model. The process and kinetic models are validated against experimental data from the literature and then used for sensitivity analyses with respect to crucial hydrodynamic parameters, correlations and assumptions. The effects of mean particle size change, grid design and its related jet-induced attrition rate on the Reducer efficiency and $\mathrm{CH}_{4}$ oxidation selectivity are studied. Therefore, this work presents a comprehensive analysis (void of parameter fitting) of the modeling framework suitable for the simulation of the reduction step in CLC. Emphasis is placed on the sensitivity of 
the model to its assumptions, parameters and process particularities, in an effort to provide an accurate and realistic framework for the design of optimal CLC Reducers. 


\section{Literature survey of bubbling bed experimental data and corresponding model}

The operation of CLC fluidized bed Reducers was approximated by a bubbling regime, shown schematically in Figure S.1 of the Supporting Information. In bubbling fluidized bed reactors, a distinct upper surface of the dense phase has been experimentally observed and simulated (Kunii and Levenspiel, 1997, 1990, 1969, 1968a, 1968b; Mahalatkar et al., 2011; Shuai et al., 2011), which is not the case for dense circulating fluidized beds. Thus, a preliminary screening of the available experimental data was performed, with the objective to identify reactor configurations that operate within the bubbling bed fluidization regime. Accordingly, the data used in this work include the studies by Jerndal et. al. (2010), Chandel et al. (2009), Iliuta et al. (2010) and Yazdanpanah et al. (2014), as summarized in Table 1. As shown in Figure S.2, the oxygen carriers used in the studies of Table 1 belong to the Geldart type B classification.

Table 1: Experimental conditions and oxygen carrier properties of the bubbling bed CLC Reducers studied

\begin{tabular}{lllll}
\hline Properties & (Jerndal et al., 2010) & (Chandel et al., 2009) & (Iliuta et al., 2010) & $\begin{array}{l}\text { (Yazdanpanah et } \\
\text { al., 2014) }\end{array}$ \\
\hline Furnace temp $\left({ }^{\circ} \mathrm{C}\right)$ & 950 & 800 & $623,645,810$ & 750 \\
\hline $\mathrm{P}(\mathrm{atm})$ & 1 & 1 & 1 & 1 \\
\hline $\mathrm{NiO} /$ Support & $40 \% \mathrm{NiO} / \mathrm{NiAl}_{2} \mathrm{O}_{4}$ & $60 \% \mathrm{NiO} / \mathrm{NiAl}_{2} \mathrm{O}_{4}$ & $15 \% \mathrm{NiO} / \mathrm{Al}_{2} \mathrm{O}_{3}$ & $60 \% \mathrm{NiO} / \mathrm{NiAl}_{2} \mathrm{O}_{4}$ \\
\hline Oxygen carrier load $(\mathrm{kg})$ & 0.015 & 2.5 & 0.3 & $6.3,10$ \\
\hline Particle size $(\mu \mathrm{m})$ & $125-180$ & 171 & 140 & 201 \\
\hline Geldart powder group & $\mathrm{B}$ & $\mathrm{B}$ & $\mathrm{B}$ & $\mathrm{B}$ \\
\hline Specific surface area $\left(\mathrm{m}^{2} / \mathrm{s}\right)$ & 0.91 & 7 & 102 & 2 \\
\hline Bulk density $\left(\mathrm{kg} / \mathrm{m}^{3}\right)$ & 2400 & 2200 & 1100 & 2050 \\
\hline Sphericity & 0.99 & 0.98 & 0.95 & 0.95 \\
\hline Fuel composition & $100 \% \mathrm{CH}_{4}$ & $100 \% \mathrm{CH}_{4}$ & $10 \%, 50 \% \mathrm{CH}_{4}$ in $\mathrm{Ar}$ & $100 \% \mathrm{CH}_{4}$ \\
\hline Gas flow rate $\left(\mathrm{m}^{3} / \mathrm{s}\right)$ & $7.50 \mathrm{E}-06$ & $2.00 \mathrm{E}-04$ & $2.00 \mathrm{E}-05$ & $1.39 \mathrm{E}-04,2.08 \mathrm{E}-04$ \\
\hline I.D. $(\mathrm{mm})$ & 22 & 96 & 46 & 130 \\
\hline Bed height $(\mathrm{m})$ & 0.03 & 0.21 & 0.23 & $0.33,0.55$ \\
\hline Reactor height $(\mathrm{m})$ & 0.5 & 1 & 0.94 & 1 \\
\hline Space time $(\mathrm{s} \mathrm{gNiO} / \mathrm{g}$ Fuel) & 1254 & 9747 & 5297 & 17374 \\
\hline
\end{tabular}

Note: * Particle sphericity depends on the shape of the OCs, ranging from 0.75 to 0.99 , roughly estimated by supporting experimental techniques, such as scanning electron microscopy.

The validity of the bubbling fluidization regime, lack of slugging, and negligible elutriation, were assessed for all the experimental data listed in Table 1. The regimes of fluidization for 
Geldart type A and B particles are shown in Figure 1, in terms of the dimensionless particle size, $d_{p}{ }^{*}=A r^{1 / 3}$, and velocity, $U^{*}=\operatorname{Re} / A r^{1 / 3}$. This analysis is based on the work of Bi and Grace (1995), updated to account for the more general correlation of Haider and Levenspiel (1989) for the particle terminal velocity, $U_{t}^{*}$. The shaded areas in Figure 1 illustrate ranges of stable operation in the corresponding hydrodynamic regime (Bubbling Fluidization, Fast Fluidization, Conveying (Jin et al., 2003), and Spouting in conical reactors (Olazar et al., 2004)). Bubbles appear at the minimum fluidization velocity for Geldart B particles and are distinct up to the onset of turbulent fluidization $\left(R e_{c}\right.$ in Figure 1), while entrainment of particles becomes significant at $R e_{s e}$.

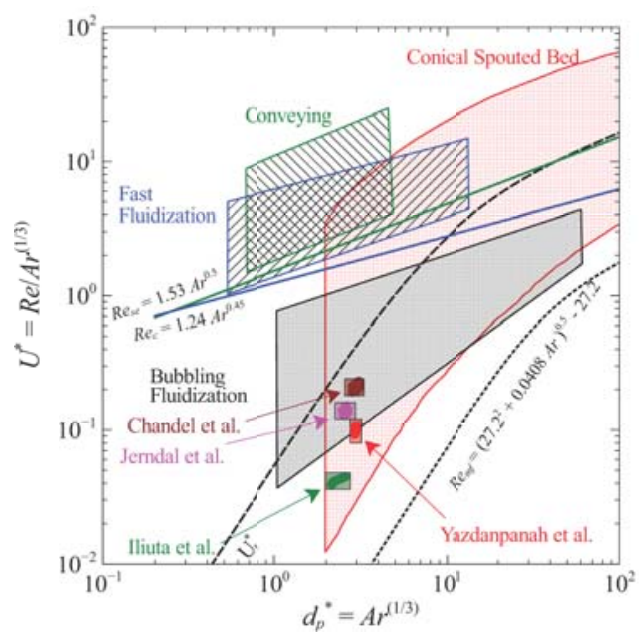

Figure 1: Regimes of gas - solid fluidization (Bi and Grace, 1995) and the corresponding fluidization regime for the data published by Chandel et al. (2009), Iliuta et al. (2010), Yazdanpanah et al. (2014)and Jerndal et al. (2010).

Depending on the bed location and reaction time (affecting temperature and gas composition), the ranges of $d_{p}{ }^{*}$ and $U^{*}$ for the units considered in this study were estimated as shown in Figure 1. These ranges correspond to loose enclosures of the conditions studied here and are in no way exclusive or deterministic. Since reaction molar change, temperature and pressure variations affect the gas velocity, the space-averaged transient velocity is shown here. In conclusion, the operating conditions of all the reactors considered in this study correspond to regimes well-below the critical velocity of elutriation, $R e_{s e}=1.53 A r^{0.5}$ (Marmo et al., 1999). In 
particular, the fluidization regimes of the reactors designed by Chandel et al. (2009), Jerndal et al. (2010), and Yazdanpanah et al. (2014) fall right into the bubbling bed regime. The operating flow regime employed by Iliuta et al. (2010) is shown to be somewhat below the bubbling bed regime, but higher than the minimum fluidization velocity. For all the units studied, slugging is not likely to occur (explored with the Yagi and Muchi criterion (Rhodes, 2008), not shown here).

\subsection{Reaction kinetics network}

The mean particle diameter of all the oxygen carriers used in the fluidized bed reactors considered in this study is below $205 \mu \mathrm{m}$. Thus, intraparticle diffusion was neglected (GarcíaLabiano et al., 2005; Han et al., 2014, 2013). The developed model utilizes the kinetic model reported in Zhou et al. (2013), which was developed on the basis of a large list of literature data on the reduction of $\mathrm{NiO}$ by $\mathrm{CH}_{4}$ in fixed bed reactors. The relevant reactions include $\mathrm{NiO}$ reduction reactions (with $\mathrm{CH}_{4}, \mathrm{H}_{2}$ and $\mathrm{CO}$ ), Ni-catalyzed reforming reactions (steam reforming, dry reforming, and water-gas shift), and Ni-catalyzed carbon formation and elimination reactions $\left(\mathrm{CH}_{4}\right.$ decomposition and carbon gasification by $\mathrm{H}_{2} \mathrm{O}$ and $\left.\mathrm{CO}_{2}\right)$. Partial oxidation products, $\mathrm{H}_{2}$ and $\mathrm{CO}$, are produced by oxygen carrier reduction reactions and $\mathrm{Ni}$-catalyzed reactions, but are further converted to $\mathrm{CO}_{2}$ and $\mathrm{H}_{2} \mathrm{O}$ via $\mathrm{NiO}$ reduction and catalytic reactions. The kinetic expressions, kinetic parameters, thermodynamic equilibrium constants, and adsorption coefficients were shown and discussed in detail in Zhou et al. (2013). The analysis therein was based on fixed bed data and, thus, amongst the objectives of this work is to explore the validity and generality of this reactions scheme, its kinetics and parameter values, as applied to fluidized bed reactors. 


\subsection{Model description}

A dynamic three-phase (bubble, emulsion and wake) model was used to simulate the dense bed hydrodynamics (Kunii and Levenspiel, 1968a, 1968b). The model considers gas bubbles flowing through a dense emulsion phase at a relative velocity given by the minimum fluidization velocity $\left(u_{m f}\right)$, with gas percolating through the bed of solids. The diameter of bubbles increases with bed height and is assumed uniform over the radial bed coordinate. The main mechanism for the circulation of solids in the bed is the rising bubbles, which carry a wake of solids (Figure S.1). A small fraction of the solids reaching the dense bed top is entrained to the freeboard, whereas the remaining solids flow downwards due to gravity, forming countercurrent flow. Therefore, a good mixing between gas and solids is established in the dense bed. Gas-solid mass exchange between the bubble/wake and emulsion phases is taken into account via diffusive and convective mass transfer. Two energy balances (bubble/wake and emulsion, respectively) are applied for the dense phase, under the assumption that the gas and solids are at the same temperature in each phase (bubble and emulsion). The temperature gradient between the two phases is determined by the interphase heat transfer plus the heat of reaction. Entrainment of the particles from the dense phase into the freeboard is considered, while elutriation of carry-over solids out of the freeboard is neglected. The freeboard region is modeled as a 1-D two-phase (gas and solid) transient plug flow reactor with axial dispersion. The composition and temperature variations in the lateral direction are neglected in the model. While some lateral variations may occur, due to imperfect mixing and other effects of the reactor walls, for a well-mixed fluidized bed system with good distribution of solid and gas, it is expected that the lateral variations are minimal and thus, a 1-D modeling approach is sufficient. The mass, energy and momentum balances of the 3-phase model are presented in Appendix A. All the correlations used for the 
estimation of the hydrodynamic variables and the properties of the gas and solids in the reactors studied are provided in the Supporting Information.

The mass and energy balances were integrated in Matlab 2013 (The Mathworks Inc., 2013). The partial differential equations (PDEs) were discretized in the axial direction using backward finite differences. The implicit DAE system was integrated over time using the open source Sundials IDA solver (Lawrence Livermore National Laboratory, 2012), which integrates the algebraic equations (gas velocity, dense phase bed height, and pressure balance equations) using a variable-order (from 1 to 5) backward differentiation method. The algebraic equations were solved using direct, dense Jacobians. The model was also developed in and validated with the equation-oriented environment of gPROMS (Process Systems Enterprise, 2012).

\section{Model validation}

The model described in Section 2 and detailed in the Appendix was applied to experimental data from the literature, presented in Table 1. It should be noted that the results discussed herein do not entail any parameter or model fitting; instead, they are pure predictions using the hydrodynamic model described in Section 2 and the kinetic model developed previously (Zhou et al., 2013). The focus of this section is to demonstrate the capability of the model to represent the literature data without further fitting, with the objective to use this model and the same reactor configurations for illustrating the impact of assumptions and model parameters on possible conclusions in terms of $\mathrm{CLC}$ effectiveness $\left(\mathrm{CO}_{2}\right.$ capture efficiency, $\mathrm{CH}_{4}$ conversion, oxygen carrier agglomeration or attrition, etc.). Therefore, all the data analyzed here use $\mathrm{CH}_{4}$ as the fuel and a $\mathrm{NiO}$ oxygen carrier. We acknowledge that small variations can occur because of the differences in the oxygen carriers used in each experimental study, but the objective of this 
analysis is to demonstrate the overall ability of the model to capture the literature data and not perfect data predictions.

Jerndal et al. (2010) performed fluidized bed CLC experiments with a spray-dried $\mathrm{NiO} / \mathrm{NiAl}_{2} \mathrm{O}_{4}$ oxygen carrier. In Figure 2, application of the model to the experimental data of Jerndal et al. at $950{ }^{\circ} \mathrm{C}$ is shown. The reactivity of the oxygen carrier appears low initially, with some $\mathrm{CH}_{4}$ slip observed, which is well captured by the model. Typically, the reduction of $\mathrm{NiO}$ is initiated by nuclei formation (Sedor et al., 2008; Zhou et al., 2014b) or the production of metallic $\mathrm{Ni}$ that catalyzes $\mathrm{CH}_{4}$ steam reforming reactions (Cabello et al., 2014) and further promote the reduction reactions. After the initial low reactivity period, the gas product at the exit of the reactor contains mostly $\mathrm{CO}_{2}$, due to the relative excess of $\mathrm{NiO}$. The overall $\mathrm{CO}_{2}$ selectivity is maintained at high levels for the entire reduction time, which is one of the benefits of performing CLC in a fluidized bed compared to a fixed-bed reactor (Zhou et al., 2014a).

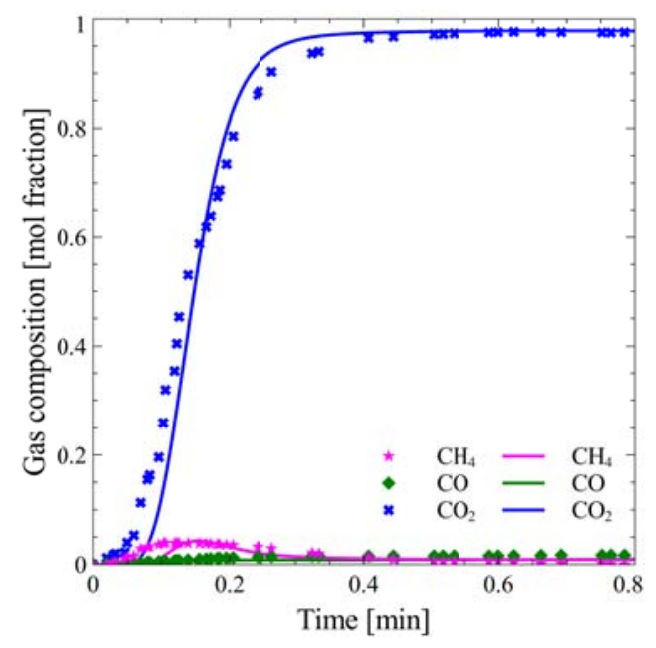

Figure 2: Chemical-looping reduction selectivity using $\mathrm{Ni} / \mathrm{NiO}$ and $\mathrm{CH}_{4}$ in the fluidized bed reactor of Jerndal et al. (2010) at $950{ }^{\circ} \mathrm{C}$.

Chandel et al. (2009) studied the reactivity of Ni- and $\mathrm{Cu} / \mathrm{Fe}-$ based oxygen carriers in a semibatch fluidized bed reactor by varying the number of redox cycles, reactor temperature ( $800-$ $\left.900{ }^{\circ} \mathrm{C}\right)$, bed inventory $\left(2.5-6 \mathrm{~kg}\right.$ ) and fuel flow, with the conclusion that $97 \% \mathrm{CO}_{2}$ capture 
efficiency was achievable in their setup. Figure 3 shows the prediction of the experimental data of the pilot-scale bubbling bed reactor of Chandel et al. with $\mathrm{NiO} / \mathrm{NiAl}_{2} \mathrm{O}_{4}$ at $800{ }^{\circ} \mathrm{C}$. Again a $\mathrm{CH}_{4}$ slip was measured (and is predicted by the model), due to the low initial oxygen carrier reactivity. A detailed sensitivity analysis in terms of the $\mathrm{CH}_{4}$ slip is presented in Section 4 . As shown in Figure 3, higher concentrations of partial oxidation products, $\mathrm{CO}$ and $\mathrm{H}_{2}$, are detected in the experimental data of Chandel et al. and are predicted by the model. The presence of CO and $\mathrm{H}_{2}$ is mainly attributed to the limited amount of oxygen carrier in the bubble phase and the thermodynamic limitations of $\mathrm{NiO}$ to completely convert $\mathrm{CH}_{4}$ to $\mathrm{CO}_{2}$ and $\mathrm{H}_{2} \mathrm{O}$.

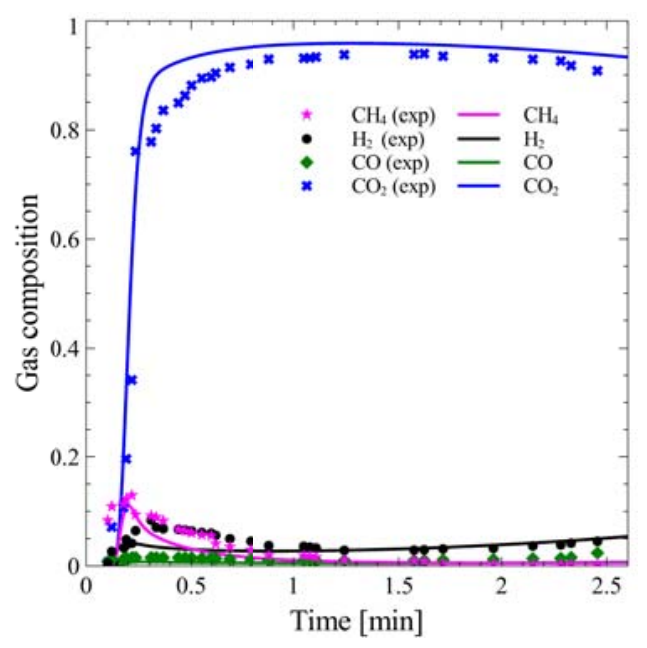

Figure 3: Chemical-looping reduction selectivity using $\mathrm{Ni} / \mathrm{NiO}$ and $\mathrm{CH}_{4}$ in the fluidized bed reactor of Chandel et al. (2009) at $800{ }^{\circ} \mathrm{C}$.

Reduction of a Ni-based oxygen carrier by $\mathrm{CH}_{4}$, was also investigated in a semi-batch fluidized bed by Iliuta et al. (2010) at $600-810^{\circ} \mathrm{C}$. Small $\mathrm{H}_{2}(1 \mathrm{~mol} \%)$ and zero $\mathrm{CO}$ emissions were detected and almost complete $\mathrm{CH}_{4}$ conversion was achieved with the outlet gas being mainly composed of $\mathrm{CO}_{2}$ and $\mathrm{H}_{2} \mathrm{O}$. Figure 4 shows the comparison of experimental data with model predictions for the gas product selectivity and solid conversion from Iliuta et al. at $623{ }^{\circ} \mathrm{C}$. The exit gas composition is well-predicted by the model. The experimentally measured, spaceaveraged $\mathrm{NiO}$ conversion ( $36 \mathrm{~mol} \% \mathrm{NiO}$ ) is also well-predicted by the model, as shown in 
Figure 4(b). The initial over-prediction of $\mathrm{H}_{2} \mathrm{O}$ could possibly be attributed to the uncertainty of the hydrodynamic regime for this system, which as discussed operates below the bubbling bed regime. A detailed analysis of the effect of bubble size on the $\mathrm{CH}_{4}$ slip in CLC is discussed in Section 4.

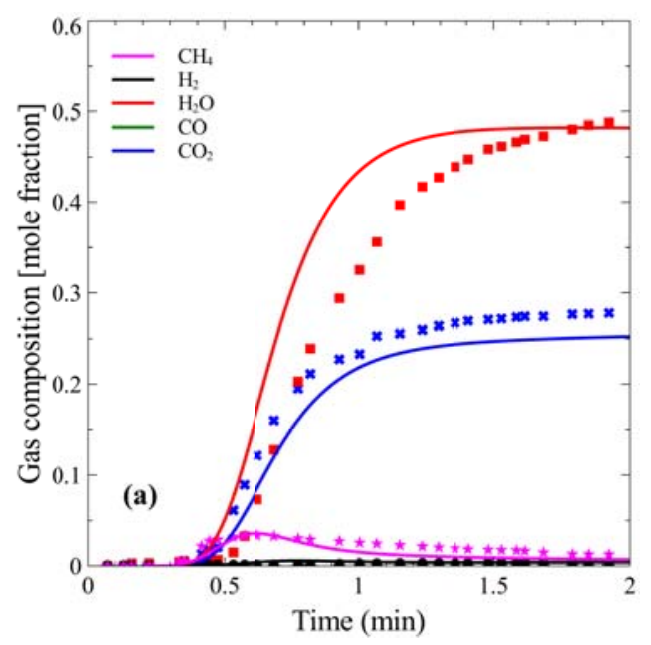

Figure 4: Chemical-looping reduction selectivity using $\mathrm{Ni} / \mathrm{NiO}$ and $\mathrm{CH}_{4}$ in the fluidized bed reactor of Iliuta et al. (2010) at $623{ }^{\circ} \mathrm{C}$. The $\mathrm{NiO}$ conversion after 2 min of reduction was measured at $36 \mathrm{~mol} \%$, while the respective model prediction was $34 \mathrm{~mol} \%$.

Yazdanpanah et al. (2014) performed CLC experiments with pure $\mathrm{CH}_{4}$ and $\mathrm{NiO} / \mathrm{NiAl}_{2} \mathrm{O}_{4}$ in a $10 \mathrm{~kW}_{\text {th }}$ pilot plant at various fuel flow rates and oxygen carrier loadings. They observed that approximately $1-3 \mathrm{~mol} \% \mathrm{CH}_{4}$ escaped the reactor unreacted, depending on the fuel flow and dense bed height. In their modeling effort, a better fit of the experimental data was obtained when solid in the bubble was considered in the model. Figure 5 presents the comparison of the experimental data with the predictions of this study for the exit gas product selectivity of Yazdanpanah et al. (2014). The $2.5-3$ min delay time in the experimental data was due to the large volume of the fluidized bed reactor and downstream system components, which was modeled in this case using the detailed reactor and downstream components geometry provided in Yazdanpanah et al. (2011). Almost complete $\mathrm{CH}_{4}$ conversion (>95\%) was achieved with negligible $\mathrm{CO}$ and $\mathrm{H}_{2}$ produced (Figure 5). Overall, the predictions of $\mathrm{CO}_{2}$ and $\mathrm{CH}_{4}$ for all the 
cases studied were satisfactory, while the $\mathrm{H}_{2}$ and $\mathrm{CO}$ were not that well captured by the model. The latter can possibly be attributed to the uncertainty in the kinetics of methane decomposition reaction (Zhou et al., 2013) and the fact that the support in the work by Yazdanpanah et al. was a $\mathrm{NiAl}_{2} \mathrm{O}_{4}$ spinel which can catalyze some of the reforming reactions.
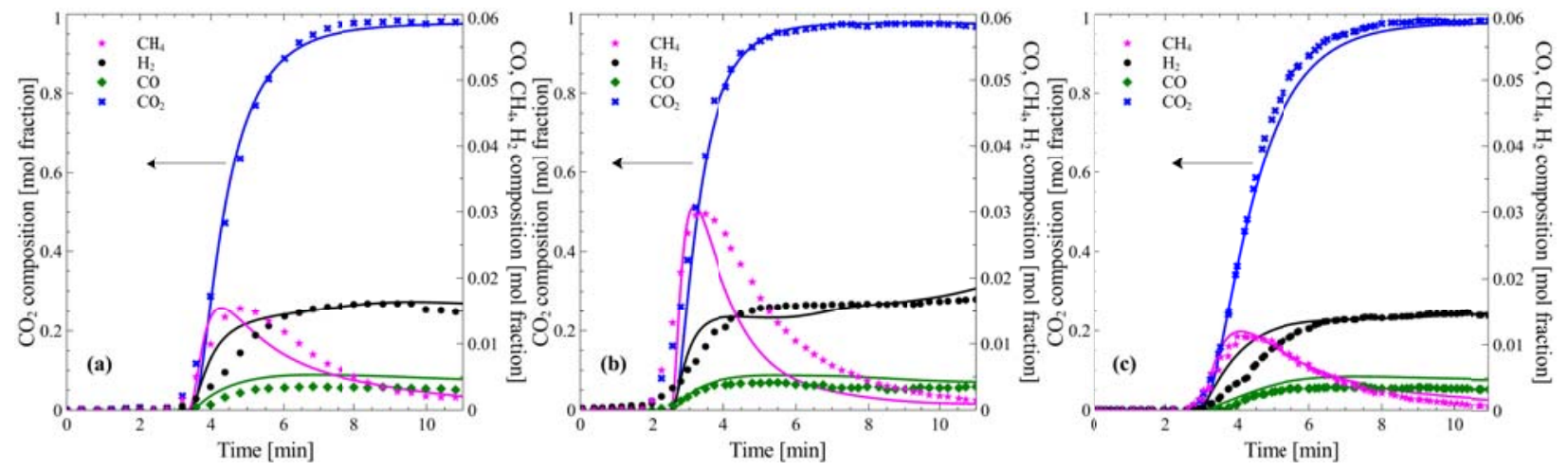

Figure 5: Chemical-looping reduction selectivity using $\mathrm{Ni} / \mathrm{NiO}$ and $\mathrm{CH}_{4}$ in the fluidized bed reactor of Yazdanpanah et al. (2014) at $800^{\circ} \mathrm{C}$.

In summary, the developed process model and the kinetics developed previously were shown to be of satisfactory agreement with experimental data from the literature, without further fitting or tuning. Thus, the reactor model can be used for design purposes, as it is predictive of the most significant CLC phenomena. On the basis of the accuracy and generality of the developed model, sensitivity analyses with respect to crucial hydrodynamic parameters and correlations, such as the bubble size, mass transfer and reactions in the freeboard region are shown in Section 4. Moreover, the effects of attrition-related particle size change and jet-induced attrition rate on the Reducer efficiency are studied.

\section{Sensitivity of the model to its assumptions and parameters}

Fluidized bed models rely heavily on the use of semi-empirical and empirical correlations for the calculation of key model parameters, such as the minimum fluidization velocity, bubble volume fraction, bubble size, interphase mass and heat transfer coefficients. A brief survey of 
some commonly used correlations employed to calculate parameters for the three-phase model is presented in Tables B.1 and B.2 in the Appendix. The objective of this Section is to analyze the sensitivity and accuracy of the model, with respect to the correlations commonly used for the prediction of bubbling bed hydrodynamics, focusing on their applicability to CLC modeling.

\subsection{Bubble/wake correlations}

The variation of the bubble diameter with bed height is typically expressed with empirical linear, exponential, and fractional relationships, as shown in Table B.1. The corresponding effect of bed height to the predicted bubble size is plotted in Figure B.1, for bed geometry and operating conditions shown therein. The deviation of the calculated bubble diameter for longer reactors is significant and needs to be analyzed beforehand (given that these correlations are empirical). As discussed previously, the accuracy of the model prediction for the data by Iliuta et al. (2010) is not high. At the same time, it should be reminded that the operating regime of this reactor falls outside the regime for stable bubbling fluidization (Figure 1). Therefore, it is of interest to evaluate the effect of bubble size on the performance of the model, at different (constant) bubble sizes. Figure 6 illustrates the effect of bubble size on the temperature difference between the bubble and emulsion phases. The indicated small and large bubbles are calculated by Eq. (S.3) and (S.4), respectively, while the medium bubble is estimated as their average. Heat transfer is enhanced for smaller bubbles due to the larger interphase area, which results in narrow temperature differences between the bubble and the emulsion phase (Figure 6). This is consistent with the results by Hatzantonis et al. (2000) and is a direct result of the heat transfer equation. The corresponding gas product distributions at the exit of the reactor are shown in Figure 6(c). Compared with the prediction of the bubble-growth model (Figure 4(a)), more unreacted $\mathrm{CH}_{4}$ is predicted by the constant bubble size model with large bubbles. Assuming 
only small bubbles, no $\mathrm{CH}_{4}$ slip is observed, as shown in Figure 6(c). Jung and Gamwo (2008) concluded that low fuel CLC conversions can be attributed to the large and fast bubbles passing through the reactor, which agrees with Figure 6(c). It is also evident that for the specific experimental configuration, the sensitivity of complete combustion products with respect to bubble size is minor. This is due to the fast kinetics of the reduction of $\mathrm{NiO}$ by $\mathrm{H}_{2}$ and $\mathrm{CO}$.
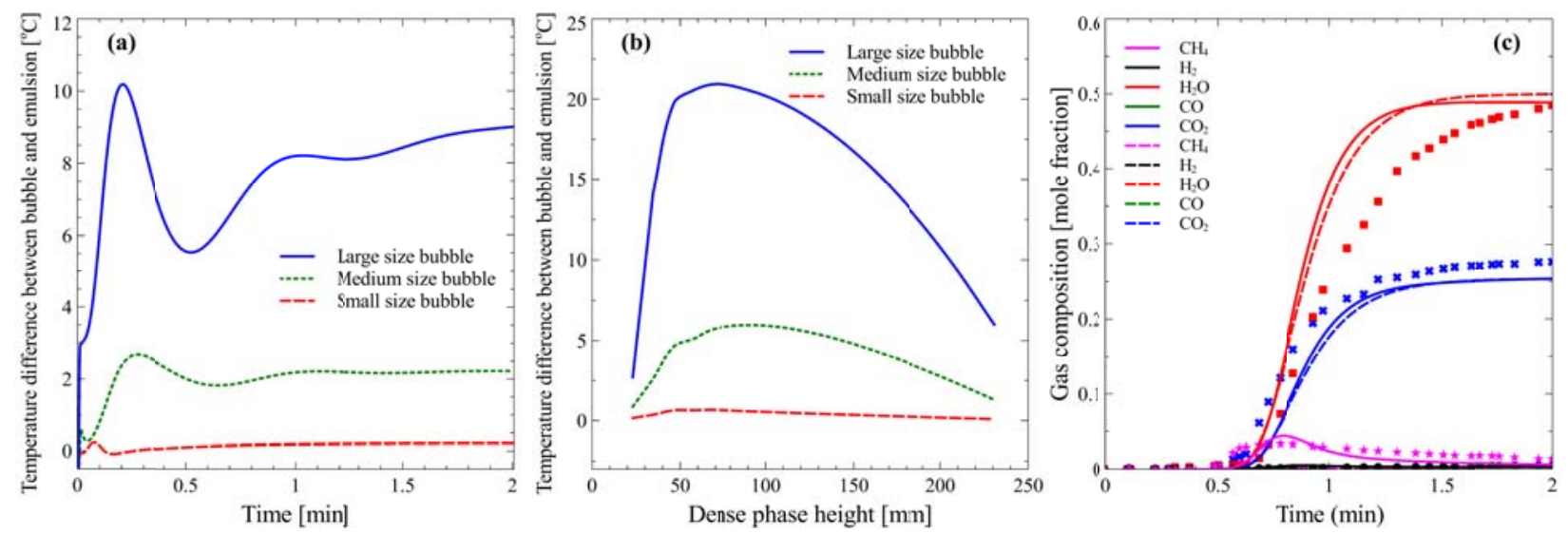

Figure 6: Effect of bubble size on the temperature difference between the bubble and emulsion phases predicted by the constant-bubble size model: (a) transient profile at reactor height of $0.22 \mathrm{~m}$ (near the dense bed top); (b) spatial profile at experiment time of $2 \mathrm{~min}$ (end of reduction step); (c) chemical-looping reduction selectivity. Data (points) and reactor configuration correspond to the fluidized bed reactor of Iliuta et al. (2010) at $623{ }^{\circ} \mathrm{C}$ with a constant-bubble size model using large bubble (solid lines) and small bubbles (dashed lines).

Yazdanpanah et al. $(2011 ; 2014)$ considered a small fraction of solids in the bubble and obtained a better prediction of their experimental data, compared to model predictions with solidfree bubbles. In order to assess the significance of the solids in the bubble wake, a comparison of the model predictions with and without consideration of the wake phase was carried out, using the reactor configuration and data by Yazdanpanah et al. Figure 7 presents the comparison of the experimental data reported by Yazdanpanah et al. and model predictions, with the assumptions of solid-containing or solid-free bubbles. Better predictions are obtained by considering the wake phase, while the model assuming solid-free bubbles predicts lower fuel conversion and $\mathrm{CO}_{2}$ selectivity. It becomes clear that consideration of the solid fraction in the bubble wake is a very 
important model parameter, especially when the reactivity and selectivity of the CLC Reducer is of interest (as is always the case in CLC).

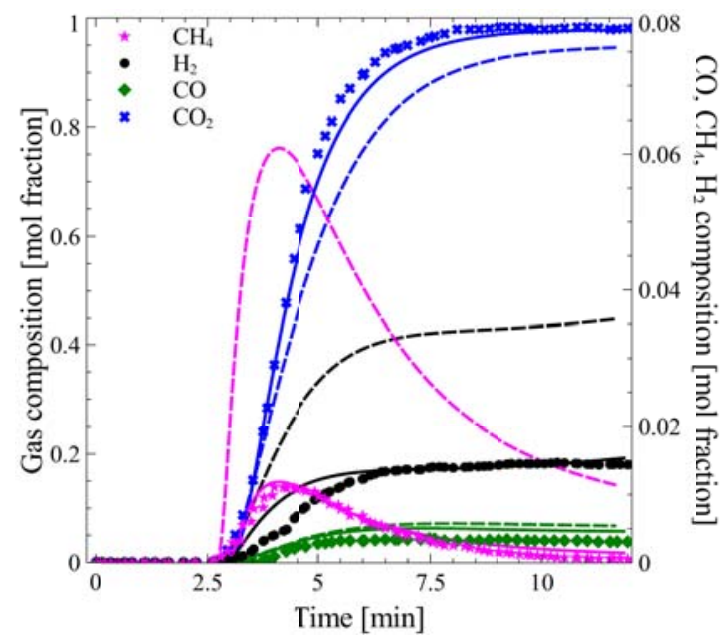

Figure 7: Effect of solid in the bubble/wake on the prediction of chemical-looping reduction selectivity using $\mathrm{Ni} / \mathrm{NiO}$ and $\mathrm{CH}_{4}$ in fluidized bed reactor of Yazdanpanah et al. (2014) at $750{ }^{\circ} \mathrm{C}$ (dashed-lines: no solid in the wake; solid-lines: with solid in the wake).

\subsection{Mass transfer correlations}

Unreacted $\mathrm{CH}_{4}$ severely impacts the greenhouse gas mitigation efficiency of CLC. In a bubbling fluidized bed reactor, unconverted $\mathrm{CH}_{4}$ is commonly seen at the initial stages of the reduction step and has been successfully simulated (Iliuta et al., 2010; Jung and Gamwo, 2008; Wang et al., 2012; Yazdanpanah et al., 2014; Zhou et al., 2013). This $\mathrm{CH}_{4}$ slip is attributed to the slow initial reduction (or reforming) kinetics of the oxygen carrier. A relatively long reaction time is required to initiate the fuel conversion by forming the $\mathrm{NiO}$ nuclei or producing sufficient amount of metallic $\mathrm{Ni}$ to catalyze $\mathrm{CH}_{4}$ reforming reactions. Thus, short contact times between the gas and solid in the bubble/wake result in unreacted $\mathrm{CH}_{4}$ slipping through fast bubbles, without reacting during the initial stage of the reduction step. As shown in Figure 3, the $\mathrm{CH}_{4}$ slip at the onset of the reduction in the reactor by Chandel et al. (2009) is relatively large. To explore the $\mathrm{CH}_{4}$ slip phenomenon in the experimental data reported by Chandel et al., the effect of the mass transfer between the bubble and emulsion is investigated. Mass transfer affects the amount 
of oxygen carrier and gas in the bubble and wake phases, and thus alters the initial reaction rates and the unconverted $\mathrm{CH}_{4}$ escaping the reactor. Two commonly used mass transfer correlations reported by Sit \& Grace (1981) and Kunii \& Levenspiel (1969) (Table B.2) were implemented in the model. Figure 8(a) presents the responses of the model, in terms of concentration differences between the bubble and emulsion, using the mass transfer correlation of Table B.2. The correlation by Kunii and Levenspiel (1969) predicts a more disparate gas composition.
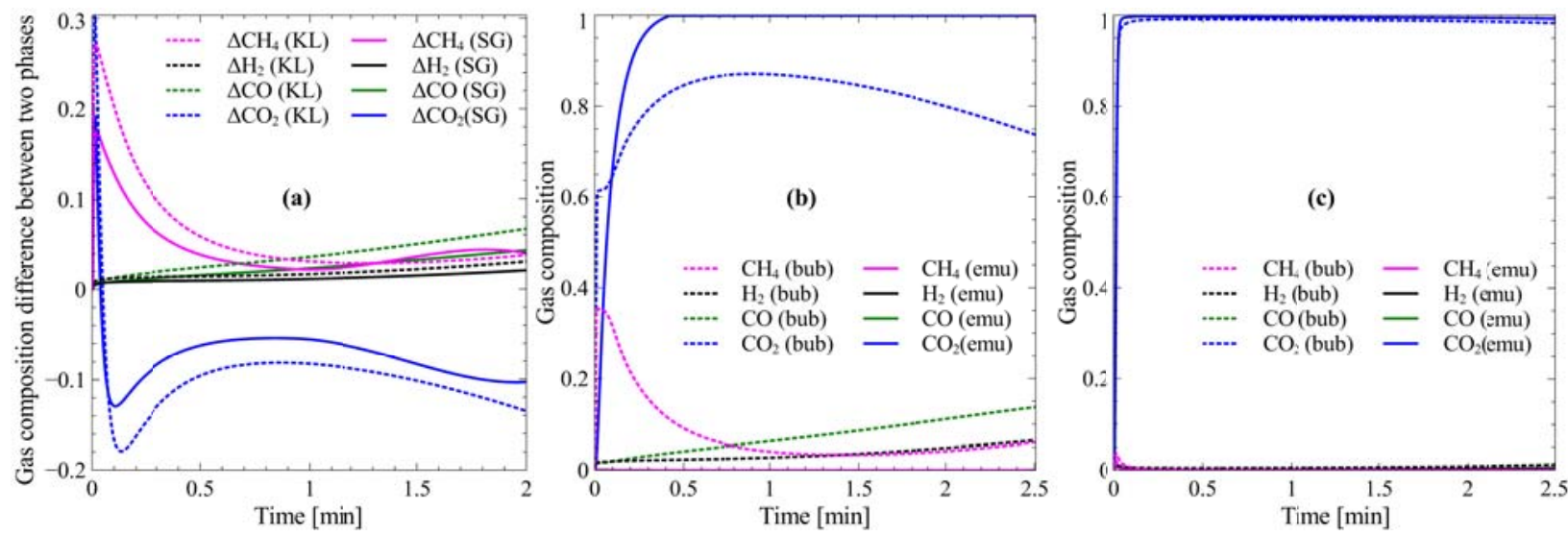

Figure 8: (a): Effect of different mass transfer correlations (Sit \& Grace (1981) - SG) and Kunii and Levenspiel (1969) - KL) on the gas composition difference between the bubble and emulsion phases. (b-c): Predicted dense phase gas composition under the assumptions of (b) no mass transfer; and (c) rapid mass transfer between the two phases. The model predictions for the bubble and the emulsion phase in Figure (c) are almost indistinguishable from each other because of the rapid mass transfer. The experimental configuration of the reactor of Chandel et al. (2009) at $800^{\circ} \mathrm{C}$ was used.

For the same data pseudo conditions (rapid transfer and no transfer) were applied, to explore the effect of mass exchange in bubbling bed CLC reducers. As shown in Figure 8(b), in the absence of mass transfer between bubbles and emulsion, a large amount of $\mathrm{CH}_{4}$ bypasses the oxygen carrier-poor bubble phase, resulting in partial oxidation products. $\mathrm{CH}_{4}$ is completely oxidized in the emulsion phase due to abundant $\mathrm{NiO}$. On the contrary, with rapid mass exchange between the two phases (Figure $8(\mathrm{c})$ ), the overall reaction rate is faster and generally similar gas 
distributions are observed in both phases. Therefore, good gas distributor designs are required to reduce the bubble size and thus enhance mass transfer and mitigate $\mathrm{CH}_{4}$ slip in CLC systems.

\subsection{Entrainment and reaction in freeboard region}

In this Section we showcase the significance of considering entrainment of the solids in the freeboard region of the CLC fluidized bed and the corresponding reactions. Figure 9 presents the axial profiles of gas composition in the Reducer (reactor configuration and oxygen carrier properties are from Iliuta et al. (2010)) with and without consideration of the reactions in the freeboard region. The axial profiles shown correspond to the experiment time instance of 0.75 min, when some $\mathrm{CO}, \mathrm{H}_{2}$ and $\mathrm{CH}_{4}$ are present at the exit of the reactor, to demonstrate the contribution of the freeboard to $\mathrm{CH}_{4}$ reactivity and $\mathrm{CO}_{2}$ selectivity. The axial gas profile of Figure 9 is shown for the dense and freeboard regions for the two cases studied. The reactions in the freeboard further convert the unreacted $\mathrm{CH}_{4}$ and improve the $\mathrm{CO}_{2}$ selectivity upon exiting the dense bed. Similar results were obtained by Abad et al. (2010), who noted that the reaction in the freeboard is significant in obtaining high combustion efficiency. Also, Pröll et al. (2009) observed that the presence of solids in the freeboard region contributes to increased fuel power for their $120 \mathrm{~kW}_{\text {th }}$ bench-scale plant.

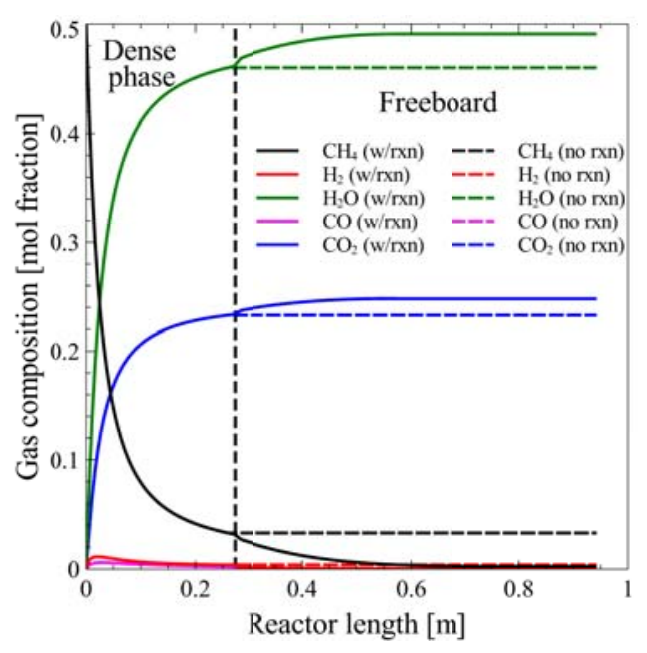


Figure 9: Axial profiles of gas composition in the chemical-looping bubbling bed Reducer of Iliuta et al. (2010) at $623{ }^{\circ} \mathrm{C}$ and experiment time $t=0.75 \mathrm{~min}$.

\subsection{Mean particle size}

The particle size distribution and mean particle size strongly affect the fluidization regime of a CLC Reducer. For instance, attrition is known to fragment and abrade the particles, especially after extended continuous operation. De Diego et al. (2007) reported that the average particle size of the oxygen carrier in the Reducer decreased from $222 \mu \mathrm{m}$ to $207 \mu \mathrm{m}$ after 100 hours of operation as a consequence of the attrition/fragmentation of larger particles, and also due to the shrinking of the particles by internal phase changes. On the contrary, Rydén et al. (2009) observed that the size of their $\mathrm{NiO} / \mathrm{Mg}-\mathrm{ZrO}_{2}$ oxygen carrier increased from $135 \mu \mathrm{m}$ to $145 \mu \mathrm{m}$ after 40 hours of testing in a fluidized bed reactor and they related that to an increase in particle porosity. Lyngfelt and Thunman (2005) and Johansson et al. (2006) tested a Ni-based oxygen carrier in a $10 \mathrm{~kW}$ chemical-looping combustor for 12 days and found that the mean particle size increased from $60 \mu \mathrm{m}$ to $114 \mu \mathrm{m}$. It is clear that attrition and particle fragmentation will have a negative impact on the CLC process economics, whereas agglomeration and oxygen carrier microstructural changes may affect the reactivity and intraparticle diffusion limitations. However, it is unclear to what degree these changes affect the reactivity in the Reducer due to changes in its hydrodynamic regime.

To investigate the effect of mean particle size on CLC performance in a bubbling bed reactor, the change in mean particle size after 4 hours and 300 hours of operation in the $10 \mathrm{~kW}$ chemicallooping plant of Lyngfelt and Thunman (2005) is modeled. For this demonstration we neglect the possible changes in the oxygen carrier microstructure, and focus on the mere effect of mean particle size on bed hydrodynamics. Figure 10 presents the gas outflow from the two phases (bubble and emulsion) and the transient solid conversion profiles with particle sizes as measured 
after 4 and 300 hours of operation $\left(d_{p}=60 \mu \mathrm{m}\right.$ and $140 \mu \mathrm{m}$, respectively) by Lyngfelt and Thunman (2005). Overall, the molar flows decrease in the bubble and increase in the emulsion as the particle size increases. Larger particles produce larger minimum fluidization velocity, smaller bubble rise velocity, and smaller fraction of bubbles in the dense phase. Slightly higher solid conversion efficiency is predicted for the system operated with larger particles (after $300 \mathrm{~h}$ operation), as shown in Figure 10(c). This indicates that better contact is achievable between the two phases for the larger particles, which can be explained by the lower fraction of gas passing through the bubbles for larger particles, when the reaction rate is essentially particle size independent (Abad et al., 2010; Adanez et al., 2012). Therefore, in addition to the effects of agglomeration (or fragmentation) of the oxygen carrier on reaction kinetics, one needs to consider the corresponding effect on hydrodynamics, which is a CLC-specific phenomenon.
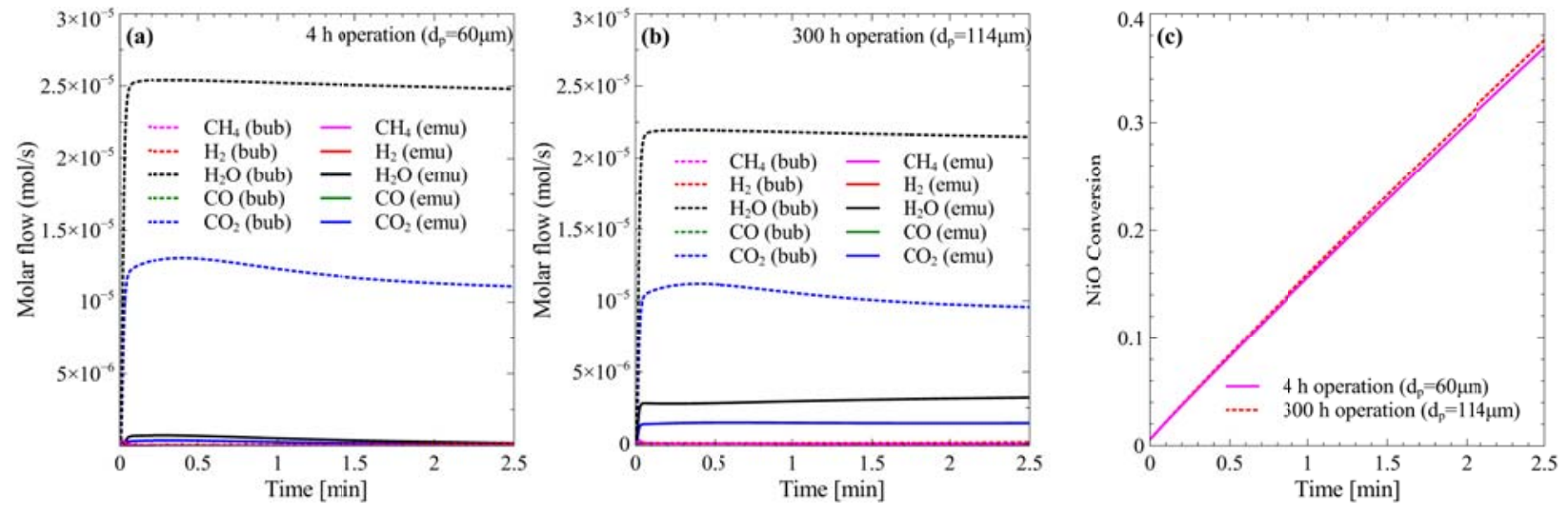

Figure 10: Predicted transient profile of $(a, b)$ gas molar flow and (c) NiO conversion in the bubble and emulsion phases after (a) $4 \mathrm{~h}$ and (b) $300 \mathrm{~h}$ of operation. The reactor data of Chandel et al. (2009) are used for the simulation with particle sizes as reported by Lyngfelt and Thunman (2005).

\subsection{Reducer Gas Distributor}

Perforated (Kronberger et al., 2005; Rifflart et al., 2011; Ryu et al., 2004) and porous (Dennis and Scott, 2010; Jerndal et al., 2009b; Rydén, 2008; Rydén et al., 2008; Wang et al., 2010) plates are two commonly used distributors in bubbling fluidized units. From the modeling 
perspective, different correlations exist for the initial bubble size of the various types of distributors, as shown in Table B.1. One of the benefits of using porous plates or perforated plates with many small orifices is their superior contacting patterns. Therefore, a CLC system with a porous plate distributor is expected to generate more complete oxidation products rather than partial products. Drawbacks of porous plate distributors include their high-pressure drop, low construction strength, low resistivity against thermal stresses and possible gradual clogging by fine particles, which hinder their use in industrial operations (Kunii and Levenspiel, 1969). Perforated plate distributors are more common in industry due to their low cost and simplicity for fabrication. Reportedly, a porous gas distributor was used in the reactor of Jerndal et al. (2010). With an outlook on CLC scale-up, the attrition rate of the CLC unit of Jerndal et al. (2009a) with an industrially practical perforated plate gas distributor is studied here, focusing only on the gird jet induced attrition (Kramp et al., 2011; Werther and Reppenhagen, 1999). For this analysis, a perforated plate was considered that matches the experimental results of Jerndal et al. (2010) at $950{ }^{\circ} \mathrm{C}$. Since synthetic oxygen carriers are typically dispersed on a support of high mechanical strength, it was assumed that the particles will be abraded rather than broken (Werther and Reppenhagen, 2003, 1999). In abrasion mode, the fines are immediately lost after their production due to the rather small size of the abrasion-produced fines $(1-3 \mu \mathrm{m})$. This loss is very significant in CLC, because of the cost of synthetic oxygen carriers (and in particular Ni). For a multi-orifice perforated plate, the loss of oxygen carrier due to fines generated by jetinduced attrition was estimated by (Werther and Reppenhagen, 1999; Werther and Xi, 1993):

$$
m_{\text {loss }, j e t}=\frac{C_{j e t} d_{P} \rho_{g} D^{6}}{d_{o r i}^{4} n_{\text {ori }}^{2}} u^{3},
$$


where $C_{j e t}$ is a particle-size independent, material-specific constant and usually measured experimentally. Here, a value of $52.6 \mathrm{E}-6 \mathrm{~s}^{2} / \mathrm{m}^{2}$ (Werther and Reppenhagen, 1999) was used, which corresponds to jet-induced attrition of a typical FCC catalyst. For the CLC experiment carried out by Jerndal et al. (2010), the estimated jet grid-induced attrition rate of the Reducer is about $1.82 \mathrm{E}-07 \mathrm{~kg} / \mathrm{s}$. Due to repeated redox cycles in a semi-batch fluidized bed the total amount of oxygen carrier decreases with time.

Figure 11 shows the $\mathrm{CO}_{2}$ selectivity in the semi-batch reactor of Jerndal et al. (2010), with a perforated plate distributor, which causes the oxygen carrier to be abraded for up to 9 hours. The $\mathrm{CO}_{2}$ selectivity in Figure 11 was calculated as $X_{\mathrm{CO}_{2}}=\frac{F_{\mathrm{CO}_{2}, \text { ut }}}{F_{\mathrm{CH}_{4}, \text { in }}}$. The minimum of selectivity at approximately $0.06 \mathrm{~min}$ of experiment time was due to the $\mathrm{CH}_{4}$ slip at the initial stage of reduction. This initial $\mathrm{CH}_{4}$ slip is attributed to the slow initial reaction kinetics to form $\mathrm{NiO}$ nuclei reaction sites or to produce metallic $\mathrm{Ni}$ to catalyze $\mathrm{CH}_{4}$ reforming reactions. As a result of the short residence time of the gas/solid in the bubble/wake, some $\mathrm{CH}_{4}$ in the fast bubbles passes through the reactor without reacting in the initial stage of the reduction step. As shown in Figure 11, the $\mathrm{CO}_{2}$ selectivity generated by reducing the $15 \mathrm{~g}$ of fresh oxygen carrier can be maintained at high level (>90mol\%) for over $1 \mathrm{~min}$. The overall $\mathrm{CO}_{2}$ selectivity drops as the oxygen carrier is fluidized for extended time. The $\mathrm{CO}_{2}$ selectivity decreases to $85 \mathrm{~mol} \%$ after oxygen carrier utilization for 9 hours in repeated reduction cycles. Therefore, in order to continuously generate $\mathrm{CO}_{2}$ of high purity in the reduction cycle for the reactor of Jerndal et al., at least $2.0 \mathrm{~g}$ oxygen carrier need to be added to the system every 3 hours. Also, note that this analysis does not consider the oxygen loss due to attrition in the Oxidizer, cyclones, loop seals and transfer lines of an integrated CLC plant, which are likely even more severe. 


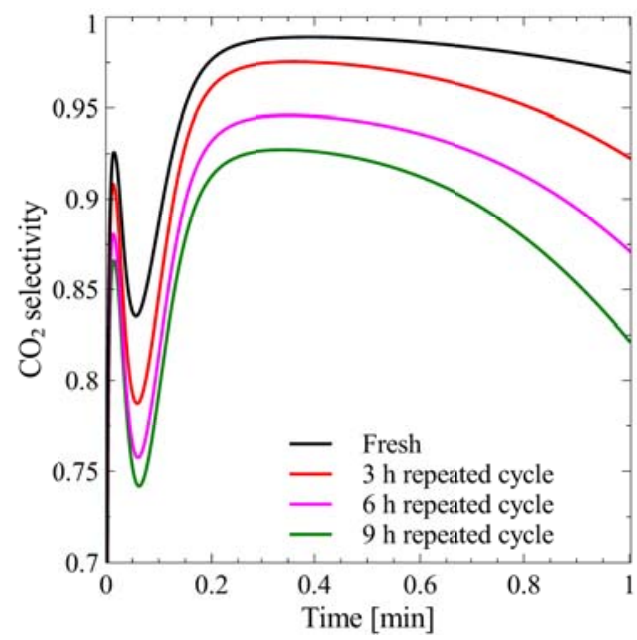

Figure 11: $\mathrm{CO}_{2}$ selectivity in a semi-batch reactor with the oxygen carrier being abraded along the multiple repeated cycles up to 9 hours. Simulations refer to the CLC reducer of Jerndal et al. (2010). 


\section{Conclusions}

A hydrodynamic model was developed with consideration of mass, energy and momentum balances, gas molar expansion, and reactions in the dense bed and the freeboard to predict the dynamic behavior of a bubbling fluidized bed reactor for chemical-looping reduction. The process and kinetic models were shown to agree well with literature experimental data, for various nickel-based oxygen carriers, and a wide range of operating conditions and reactor geometries. Sensitivity analyses were performed on the basis of the validated process model. It was found that smaller bubbles are desirable for their rapid heat transfer and enhanced fuel combustion efficiency. The entrainment and reactivity in the freeboard region was shown to significantly improve the overall solid conversion and fuel combustion efficiency. The effect of the mass transfer between the bubble and emulsion phases on the dynamic behavior of the reactor was quantified and is a significant measure of the fuel conversion in the bubble phase. Furthermore, the impact of extended continuous fluidization on the average particle size and the reactor dynamics was explored. The effect of the jet-induced attrition rate on $\mathrm{CO}_{2}$ selectivity was estimated to be significant. Overall, this process model can be used as a predictive simulation and design tool for chemical-looping reduction in a bubbling fluidized bed. Further application of this process model on $\mathrm{Cu}$-based chemical-looping processes, implementation in system-level CLC process design studies and scale-up of the fluidized bed reactor are underway (Nordness et al., 2014; Zhou et al., 2015, 2014c).

\section{Acknowledgments}

This material is based upon work supported by the National Science Foundation under Grant No. 1054718 . 


\section{NOMENCLATURE}

$A_{l k} \quad$ binary interaction parameter

$A_{R} \quad$ cross-sectional area of the reactor tube $\left[\mathrm{m}^{2}\right]$

$C_{\text {dis }}$ discharge coefficient

$C_{j, b} \quad$ bulk concentration of gaseous reactant $\left[\mathrm{kmol} / \mathrm{m}^{3}\right]$

$C_{j, b} \quad$ solid concentration in the upper limit of the dense phase

$C_{S, f} \quad$ solid concentration in the freeboard

$C_{g, b} \quad$ total gas concentration in the bubble phase $\left[\mathrm{kmol} / \mathrm{m}^{3}\right]$

$C_{g, e} \quad$ total gas concentration in the emulsion phase $\left[\mathrm{kmol} / \mathrm{m}^{3}\right]$

$C p_{b} \quad$ heat capacity of the gas mixture of the bubble phase [J/mol K]

$C p_{e} \quad$ heat capacity of the gas mixture of the emulsion phase $[\mathrm{J} / \mathrm{mol} \mathrm{K}]$

$C p_{f} \quad$ heat capacity of the gas mixture of the freeboard region $[\mathrm{J} / \mathrm{mol} \mathrm{K}]$

$C_{i, w} \quad$ concentration of solid species $i$ in wake phase

$C_{i, e} \quad$ concentration of solid species $i$ in emulsion phase

$C_{i, f} \quad$ concentration of solid species $i$ in emulsion phase

$C p_{i, w}$ heat capacity of the solid species $i$ in the wake phase

$C p_{i, e} \quad$ heat capacity of the solid species $i$ in the emulsion phase

$C p_{i, f} \quad$ heat capacity of the solid species $i$ in the freeboard region

$d_{b} \quad$ bubble diameter [m]

$d_{b e} \quad$ equilibrium bubble diameter $[\mathrm{m}]$

$d_{b 0} \quad$ initial bubble diameter [m]

$d_{b m} \quad$ maximum bubble diameter [m]

$d_{p} \quad$ particle diameter $[\mathrm{m}]$

$d_{\text {ori }} \quad$ orifice diameter $[\mathrm{m}]$

$D \quad$ reactor diameter $[\mathrm{m}]$

$D_{a x, j, f}$ axial dispersion coefficient of species $j$ in the freeboard region $\left[\mathrm{m}^{2} / \mathrm{s}\right]$

$D_{i j} \quad$ binary gas phase diffusivities $\left[\mathrm{cm}^{2} / \mathrm{s}\right]$

$D_{j} \quad$ diffusion coefficient of component $j$ in the mixture $\left[\mathrm{m}^{2} / \mathrm{s}\right]$

$f_{s} \quad$ solids-wall friction coefficient

$G_{s} \quad$ mass flux of solid $\left[\mathrm{kg} / \mathrm{m}^{2} \mathrm{~s}\right]$

$G \quad$ mass flux of gas $\left[\mathrm{kg} / \mathrm{m}^{2} \mathrm{~s}\right]$ 
$h \quad$ length element

$h_{p c} \quad$ particle convective component of $U\left[\mathrm{~J} / \mathrm{m}^{2} \mathrm{~K} \mathrm{~s}\right]$

$h_{g c} \quad$ gas convective component of $U\left[\mathrm{~J} / \mathrm{m}^{2} \mathrm{~K} \mathrm{~s}\right]$

$h_{r} \quad$ radiative heat transfer component of $U\left[\mathrm{~J} / \mathrm{m}^{2} \mathrm{~K} \mathrm{~s}\right]$

$H \quad$ reactor height $[\mathrm{m}]$

$H_{d} \quad$ dense phase height [m]

$H_{f} \quad$ freeboard region height $[\mathrm{m}]$

$H_{m f} \quad$ dense phase height at minimum fluidization [m]

$H_{b e, j} \quad$ heat exchange coefficient between bubble-emulsion $\left[\mathrm{J} / \mathrm{s} \mathrm{m}^{3} \mathrm{~K}\right]$

$H_{b c, j} \quad$ heat exchange coefficient between bubble-cloud $\left[\mathrm{J} / \mathrm{s} \mathrm{m}^{3} \mathrm{~K}\right]$

$H_{c e, j} \quad$ heat exchange coefficient between cloud-emulsion $\left[\mathrm{J} / \mathrm{s} \mathrm{m}^{2} \mathrm{~K}\right]$

$K_{b e, j} \quad$ gas exchange coefficient between bubble-emulsion $\left[\mathrm{s}^{-1}\right]$

$K_{e b, j} \quad$ gas exchange coefficient between emulsion-bubble $\left[\mathrm{s}^{-1}\right]$

$K_{b c, j} \quad$ gas exchange coefficient between bubble-cloud [ $\mathrm{s}^{-1}$ ]

$K_{c e, j} \quad$ gas exchange coefficient between cloud-emulsion $\left[\mathrm{s}^{-1}\right]$

$K_{e w, i}$ coefficient of solid exchange between emulsion and wake per unit of solid volume in emulsion $\left[\mathrm{s}^{-1}\right]$

$K_{w e, i} \quad$ coefficient of solid exchange between wake and emulsion per unit of solid volume in wake $\left[\mathrm{s}^{-1}\right]$

$k_{g, b} \quad$ thermal conductivity of the gas mixture in the bubble phase [W/m K]

$k_{g, e} \quad$ thermal conductivity of the gas mixture in the emulsion phase [W/m K]

$M_{i} \quad$ molecular mass of solid component $i,[\mathrm{~kg} / \mathrm{kmol}]$

$m_{\text {loss }, \text { jet }}$ jet-induced attrition rate, $[\mathrm{kg} / \mathrm{s}]$

$n_{\text {ori }} \quad$ number of orifice openings in the distributor

$n \quad$ total number of gas species

$P \quad$ pressure [bar]

$P_{c} \quad$ critical pressure [bar]

$p_{f s} \quad$ solids-wall frictional pressure [bar]

$R_{q, b} \quad$ rate for reaction $q$ per unit mass of the oxygen carrier in bubble phase [ $\mathrm{kmol} / \mathrm{kg}_{\text {carrier } \mathrm{s}}$ ]

$R_{q, e} \quad$ rate for reaction $q$ per unit mass of the oxygen carrier in emulsion phase $\left[\mathrm{kmol} / \mathrm{kg}_{\text {carrier }} \mathrm{s}\right.$ ]

$R_{q, f} \quad$ rate for reaction $q$ per unit mass of the oxygen carrier in freeboard region $\left[\mathrm{kmol} / \mathrm{kg}_{\text {carrier }} \mathrm{s}\right]$ 


$\begin{array}{ll}t & \text { time [s] } \\ T_{\text {bed }} & \text { bed temperature [K] } \\ T_{b} & \text { temperature of the bubble phase }[\mathrm{K}] \\ T_{c} & \text { critical temperature }[\mathrm{K}] \\ T_{r} & \text { reduced temperature } \\ T_{e} & \text { temperature of the emulsion phase }[\mathrm{K}] \\ T_{w a l l} & \text { temperature at the wall }[\mathrm{K}] \\ T_{f} & \text { temperature of the freeboard region }[\mathrm{K}] \\ T_{0} & \text { initial temperature }[\mathrm{K}] \\ u_{m f} & \text { minimum fluidization velocity }[\mathrm{m} / \mathrm{s}] \\ u_{b} & \text { bubble velocity }[\mathrm{m} / \mathrm{s}] \\ u_{e} & \text { emulsion velocity }[\mathrm{m} / \mathrm{s}] \\ u_{S} & \text { downward solid velocity in emulsion }[\mathrm{m} / \mathrm{s}] \\ u_{s, f} & \text { solid velocity in freeboard }[\mathrm{m} / \mathrm{s}] \\ u_{g, f} & \text { gas velocity in freeboard }[\mathrm{m} / \mathrm{s}] \\ u_{s g} & \text { superficial gas velocity }[\mathrm{m} / \mathrm{s}] \\ u_{t} & \text { single particle terminal velocity }[\mathrm{m} / \mathrm{s}] \\ W_{O C} & \text { oxygen carrier load }[\mathrm{kg}] \\ X & \text { NiO conversion } \\ y_{j} & \text { gas fraction of species } j \\ z & \text { reactor coordinate }[\mathrm{m}] \\ U & \text { overall heat transfer coefficient }\left[\mathrm{J} / \mathrm{m}{ }^{2} \mathrm{~K} \mathrm{~s}\right]\end{array}$

\section{Greek letters}

$\Gamma \quad$ reduced inverse thermal conductivity

$\alpha \quad$ fraction of wake in bubbles

$\varepsilon \quad$ numerical constant, near unity

$\kappa_{\text {bed }} \quad$ emissivity of the bed surface, $0.5-0.9$

$\kappa_{\text {wall }}$ emissivity of heat transfer surface, $0.02-0.2$ (light surface), $0.8-0.85$ (dark surface)

$\kappa_{b-w} \quad$ generalized emissivity

$\varepsilon_{\text {bed }} \quad$ dense bed porosity 


$$
\begin{array}{ll}
\varepsilon_{m f} & \text { minimum fluidization porosity } \\
\varepsilon_{f} & \text { freeboard porosity } \\
\mu_{m} & \text { viscosity of the gas mixture }\left[\mathrm{N}-\mathrm{s} / \mathrm{m}^{2}\right] \\
\sigma & \text { Stefan-Boltzmann constant, } 5.67 \mathrm{E}-8\left[\mathrm{~W} / \mathrm{m}^{2} / \mathrm{K}^{4}\right] \\
\delta & \text { fraction of bubbles in bed } \\
\rho_{p} & \text { solid density }\left[\mathrm{kg} / \mathrm{m}^{3}\right] \\
\rho_{g} & \text { gas density }\left[\mathrm{kg} / \mathrm{m}^{3}\right] \\
\xi_{g s} & \text { gas-solid contact efficiency in the freeboard region } \\
\phi & \text { particle sphericity } \\
\lambda_{a x} & \text { axial heat dispersion coefficient }[\mathrm{W} / \mathrm{m} \mathrm{K}] \\
\lambda_{j} & \text { thermal conductivity of the species } j[\mathrm{~W} / \mathrm{m} \mathrm{K}] \\
\lambda_{s} & \text { thermal conductivity of the oxygen carrier }[\mathrm{W} / \mathrm{m} \mathrm{K}] \\
\lambda_{t r . j} & \text { translational thermal conductivity for species } j \\
\Delta H_{q, b} & \text { heat of reaction } q \text { in the bubble phase[J } / \mathrm{mol}] \\
\Delta H_{q, e} & \text { heat of reaction } q \text { in the emulsion phase[J } / \mathrm{mol}] \\
\Delta H_{q, f} & \text { heat of reaction } q \text { in the freeboard region }[\mathrm{J} / \mathrm{mol}] \\
\Delta p_{d i s} & \text { pressure drop across the distributor }[\mathrm{Pa}] \\
\Delta p_{b e d} & \text { pressure drop across the bed [Pa] }
\end{array}
$$

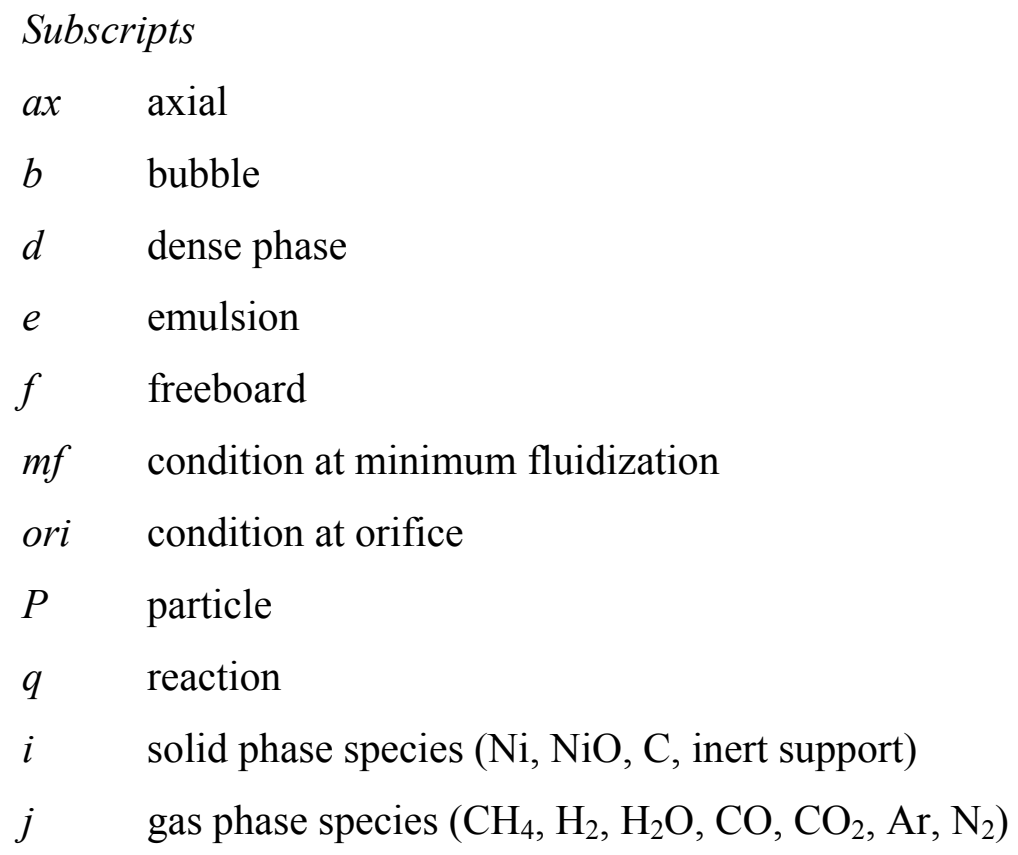




\section{APPENDIX A: Model equations}

The mass, energy and momentum equations of the model presented are provided in the following. All the hydrodynamic parameters and gas and solids properties are provided in the Supporting Information with Notation and References reported herein.

\section{Mass balance}

The following partial differential equations describe mass transfer by convection, exchange between phases, cross-flow and the reaction terms. The cross-flow between phases is caused by variation in bubble and emulsion properties with height, with $\lambda$ determining the direction of cross-flow (Sane et al., 1996).

Gas in the bubble phase:

$$
\begin{aligned}
& \left(\delta+\alpha \delta \varepsilon_{m f}\right) \frac{\partial C_{j, b}}{\partial t}+\frac{\partial\left(u_{b}\left(\delta+\alpha \delta \varepsilon_{m f}\right) C_{j, b}\right)}{\partial z}= \\
& K_{j, b e}\left(C_{j, e}-C_{j, b}\right)\left(\delta+\alpha \delta \varepsilon_{m f}\right)+\left(\lambda_{1} C_{j, b}+\lambda_{2} C_{j, e}\right) \frac{\partial\left(u_{b}\left(\delta+\alpha \delta \varepsilon_{m f}\right)\right)}{\partial z}+R_{j, b}\left(C_{j, b}\right) \rho_{P} \alpha \delta\left(1-\varepsilon_{m f}\right)
\end{aligned}
$$

Gas in the emulsion phase:

$$
\begin{aligned}
& (1-\delta-\alpha \delta) \varepsilon_{m f} \frac{\partial C_{j, e}}{\partial t}+\frac{\partial\left(u_{e}(1-\delta-\alpha \delta) \varepsilon_{m f} C_{j, e}\right)}{\partial z}= \\
& K_{j, e b}\left(C_{j, b}-C_{j, e}\right)(1-\delta-\alpha \delta) \varepsilon_{m f}-\left(\lambda_{1} C_{j, b}+\lambda_{2} C_{j, e}\right) \frac{\partial\left(u_{b}\left(\delta+\alpha \delta \varepsilon_{m f}\right)\right)}{\partial z}+R_{j, e}\left(C_{j, e}\right) \rho_{P}(1-\delta-\alpha \delta)\left(1-\varepsilon_{m f}\right)
\end{aligned}
$$

Solid in the wake phase:

$$
\begin{aligned}
& \alpha \delta\left(1-\varepsilon_{m f}\right) \rho_{P} \frac{\partial C_{i, w}}{\partial t}+\frac{\partial\left(u_{b} \alpha \delta\left(1-\varepsilon_{m f}\right) \rho_{P} C_{i, w}\right)}{\partial z}= \\
& K_{i, w e}\left(C_{i, e}-C_{i, w}\right) \rho_{P} \alpha \delta\left(1-\varepsilon_{m f}\right)+\left(\lambda_{1} C_{i, w}+\lambda_{2} C_{i, e}\right) \frac{\partial\left(u_{b} \alpha \delta\left(1-\varepsilon_{m f}\right) \rho_{P}\right)}{\partial z}+ \\
& R_{i, w} M_{i} \rho_{P} \alpha \delta\left(1-\varepsilon_{m f}\right)
\end{aligned}
$$

Solid in the emulsion phase: 


$$
\begin{aligned}
& (1-\delta-\alpha \delta)\left(1-\varepsilon_{m f}\right) \rho_{P} \frac{\partial C_{i, e}}{\partial t}+\frac{\partial\left(u_{s}(1-\delta-\alpha \delta)\left(1-\varepsilon_{m f}\right) \rho_{P} C_{i, e}\right)}{\partial z}= \\
& K_{i, e w}\left(C_{i, w}-C_{i, e}\right)(1-\delta-\alpha \delta)\left(1-\varepsilon_{m f}\right) \rho_{P}-\left(\lambda_{1} C_{i, w}+\lambda_{2} C_{i, e}\right) \frac{\partial\left(u_{b} \alpha \delta\left(1-\varepsilon_{m f}\right) \rho_{P}\right)}{\partial z}+ \\
& R_{i, w} M_{i} \rho_{P}(1-\delta-\alpha \delta)\left(1-\varepsilon_{m f}\right)
\end{aligned}
$$

Gas in the freeboard:

$\varepsilon_{f} \frac{\partial C_{j, f}}{\partial t}+u_{g, f} \frac{\partial C_{j, f}}{\partial z}=\varepsilon_{f} \frac{\partial}{\partial z}\left(D_{a x, j, f} \frac{\partial C_{j, f}}{\partial z}\right)+\left(1-\varepsilon_{f}\right) R_{j, f} \rho_{P}$

Solid in the freeboard:

$\frac{\partial C_{i, f}}{\partial t}+u_{s, f} \frac{\partial C_{i, f}}{\partial z}=R_{i, f} M_{i}$

\section{Energy balance}

The energy balance considers separate temperature profiles for the bubble and emulsion phases in the model. A detailed discussion and the temperature profile inside the emulsion and bubble phases of the fluidized bed designed by Chandel et al. (2009) was shown previously.(Zhou et al., 2014a) It should be noted that the temperature fluctuations for all the reactors considered in this study are relatively small $\left(\Delta \mathrm{T}<80{ }^{\circ} \mathrm{C}\right)$. Therefore, the energy balance can be neglected if one needs to reduce the complexity of the proposed model. However, the energy balance has to be included when significant temperature fluctuations might occur; in particular in scale-up bubbling fluidized bed analyses. The energy balance follows in accordance with the three-phase theory.

Bubble phase: 


$$
\begin{aligned}
& \left(\left(\delta+\alpha \delta \varepsilon_{m f}\right) C p_{b} C_{g, b}+\alpha \delta\left(1-\varepsilon_{m f}\right) \rho_{P} \sum C p_{i, w} C_{i, w} / M_{i}\right) \frac{\partial T_{b}}{\partial t}+ \\
& \left(\left(\delta+\alpha \delta \varepsilon_{m f}\right) C_{g, b} C p_{b} u_{b}+\alpha \delta\left(1-\varepsilon_{m f}\right) u_{b} \rho_{P} \sum C p_{i, w} C_{i, w} / M_{i}\right) \frac{\partial T_{b}}{\partial z}= \\
& \left(\delta+\alpha \delta \varepsilon_{m f}\right) \sum y_{j} H_{b e}\left(T_{e}-T_{b}\right)+\alpha \delta\left(1-\varepsilon_{m f}\right) \sum\left(-\Delta H_{q, b}\right)\left(-R_{q, b}\right) \rho_{P}+ \\
& \left(\lambda_{1} T_{b} C p_{b} C_{g, b}+\lambda_{2} T_{e} C p_{e} C_{g, e}\right) \frac{\partial}{\partial z}\left(u_{b}\left(\delta+\alpha \delta \varepsilon_{m f}\right)\right) \\
& +\sum\left(\lambda_{1} T_{b} C p_{i, w} C_{i, w} / M_{i}+\lambda_{2} T_{e} C p_{i, e} C_{i, e} / M_{i}\right) \frac{\partial}{\partial z}\left(u_{b} \alpha \delta\left(1-\varepsilon_{m f}\right) \rho_{\mathrm{P}}\right)
\end{aligned}
$$

Emulsion phase:

$$
\begin{aligned}
& \left((1-\delta-\alpha \delta) \varepsilon_{m f} C p_{e} C_{g, e}+\frac{\rho_{P}(1-\delta-\alpha \delta)\left(1-\varepsilon_{m f}\right) \sum C_{i, e} C p_{i, e}}{M_{i}}\right) \frac{\partial T_{e}}{\partial t}+ \\
& \left((1-\delta-\alpha \delta) \varepsilon_{m f} C_{g, e} C p_{e} u_{e}+\frac{\rho_{P}(1-\delta-\alpha \delta)\left(1-\varepsilon_{m f}\right) u_{s} \sum C_{i, e} C p_{i, e}}{M_{i}}\right) \frac{\partial T_{e}}{\partial z} \\
& =(1-\delta-\alpha \delta) \varepsilon_{m f} \sum y_{j} H_{j, e b}\left(T_{b}-T_{e}\right)+(1-\delta-\alpha \delta)\left(1-\varepsilon_{m f}\right) \sum\left(-\Delta H_{q, e}\right)\left(-R_{q, e}\right) \rho_{P} \\
& -\left(\lambda_{1} T_{b} C p_{b} C_{g, b}+\lambda_{2} T_{e} C p_{e} C_{g, e}\right) \frac{\partial}{\partial z}\left(u_{b}\left(\delta+\alpha \delta \varepsilon_{m f}\right)\right)- \\
& \sum\left(\lambda_{1} T_{b} C p_{i, w} \frac{C_{i, w}}{M_{i}}+\frac{\lambda_{2} T_{e} C p_{i, e} C_{i, e}}{M_{i}}\right) \frac{\partial}{\partial z}\left(u_{b} \alpha \delta\left(1-\varepsilon_{m f}\right) \rho_{\mathrm{P}}\right)+\frac{U\left(T_{w a l l}-T_{e}\right)}{H_{d}}
\end{aligned}
$$

Freeboard region:

$$
\begin{aligned}
& \left(\varepsilon_{f} C p_{f} C_{g, f}+\left(1-\varepsilon_{f}\right) \rho_{P} \sum C p_{i, f} C_{i, f} / M_{i}\right) \frac{\partial T_{f}}{\partial t}+ \\
& \left(\varepsilon_{f} C p_{f} C_{g, f} u_{g, f}+\left(1-\varepsilon_{f}\right) \rho_{P} \sum C p_{f, s, i} C_{f, s, i} u_{s, f} / M_{i}\right) \frac{\partial T_{f}}{\partial z}= \\
& \varepsilon_{f} \frac{\partial}{\partial z}\left(\lambda_{a x} \frac{\partial T_{f}}{\partial z}\right)+\left(1-\varepsilon_{f}\right) \rho_{P} \sum\left(-\Delta H_{q, f}\right)\left(-R_{q, f}\right)-4 U\left(T_{f}-T_{\text {wall }}\right) / D
\end{aligned}
$$

\section{Momentum balance}

A pressure gradient analysis (Bollas et al., 2002) is used in this study. The static head of solids is the dominant contribution, while the pressure drop caused by solids-wall friction 
(Kqnno and Saito, 1969) and static head of gas are also considered. Gas-wall frictional pressure is insignificant (Bollas et al., 2002) and thus neglected in this study.

$$
\begin{aligned}
-\frac{d p}{d z} & =\frac{d p_{f s}}{d z}+\left(1-\varepsilon_{b e d}\right) \rho_{P} g+\varepsilon_{b e d} \rho_{g} g, \\
\frac{d p_{f s}}{d z} & =\frac{2 f_{s} G_{s}^{2}}{D \rho_{P}\left(1-\varepsilon_{b e d}\right)},
\end{aligned}
$$

with the friction coefficient for the solids phase estimated by

$$
f_{s}=\frac{0.0285 \sqrt{g D}}{\left[\frac{G_{s}}{\rho_{P}\left(1-\varepsilon_{b e d}\right)}\right]} .
$$

\section{Boundary and initial conditions}

The boundary and initial conditions are as follows:

$$
\begin{array}{ll}
t=0 & C_{\text {inert }}=C_{\text {inert }}(t=0), C_{j}=0 j=\mathrm{CH}_{4}, \mathrm{H}_{2}, \mathrm{CO}, \mathrm{CO}_{2}, \mathrm{H}_{2} \mathrm{O}, C_{N i O}=C_{N i O}(t=0), C_{N i}=0, C_{C}=0, \\
& T_{b}=T_{e}=T_{f}=T_{0} \\
z=0 & C_{C H 4}=C_{C H 4, i n}, C_{\text {inert }}=C_{\text {inert }, i n}, C_{j}=0, j=\mathrm{H}_{2}, \mathrm{CO}, \mathrm{CO}_{2}, \mathrm{H}_{2} \mathrm{O}, C_{i, w}=C_{i, e}, T_{b}=T_{e}=T_{\text {inlet }} \\
z=H_{d} & C_{i, e}=C_{i, w},\left.P\right|_{z=H d}=P_{\text {out }}
\end{array}
$$

\section{APPENDIX B: Model correlations examined in this study}

The hydrodynamic correlations and property methods used in this work are provided in the Supporting Information. Here we provide a summary of the available correlations for the estimation of the bubble size in bubbling fluidized beds (Table B.1) and for the estimation of the mass transfer between the bubble and the emulsion phases. The sensitivity of the CLC Reducer model with respect to these correlations is discussed in detail in Section 4. 
Table B.1: Bubble size correlations applicable to Gerdart B particles

\begin{tabular}{|c|c|c|c|}
\hline Ref. & Correlation & Initial value & Applicable conditions \\
\hline $\begin{array}{l}\text { (Werther, } \\
\text { 1976) }\end{array}$ & $d_{b}=d_{b 0}\left(1+27.2\left(u-u_{m f}\right)\right)^{\frac{1}{3}}(1+6.84 h)^{1.21}$ & $d_{b o}=0.00835$ & $D>0.2 \mathrm{~m}, d_{P}=100-350$ \\
\hline $\begin{array}{l}\text { (Darton, } \\
1977)\end{array}$ & $d_{b}=0.54\left(u-u_{m f}\right)^{0.4}\left(h+4 \sqrt{A_{0}}\right)^{0.8} g^{-0.2}$ & - & $\begin{array}{l}A_{0}=0.000056 \mathrm{~m}^{2} \text { (porous plate) } \\
D=0.1-1.2 \mathrm{~m}, d_{P}=75-470, \\
u_{m f}=0.01-0.3 \mathrm{~m} / \mathrm{s}, u-u_{m f} \\
=0.036-0.7 \mathrm{~m} / \mathrm{s}\end{array}$ \\
\hline (Rowe, 1976) & $d_{b}=\left(u-u_{m f}\right)^{0.5}\left(h+h_{0}\right)^{0.75} g^{-0.25}$ & - & $\begin{array}{l}D=0.3-1.3 \mathrm{~m}, d_{P}=39-320 \\
u_{m f}=0.0034-0.098 \mathrm{~m} / \mathrm{s} \\
u-u_{m f}=0.011-0.154 \mathrm{~m} / \mathrm{s} \\
h_{0}=0.772+0.006 h \text { (perforated } \\
\text { plate) } ; h_{0}=0 \text { (porous plate) }\end{array}$ \\
\hline $\begin{array}{l}\text { (Mori and } \\
\text { Wen, 1975) }\end{array}$ & $d_{b}=d_{b m}-\left(d_{b m}-d_{b 0}\right) \exp \left(-\frac{0.3 h}{D}\right)$ & \multirow{2}{*}{$\begin{array}{l}d_{b 0}=\frac{3.77\left(u-u_{m f}\right)^{2}}{g} \\
\text { (porous plate) } \\
d_{b 0}=0.347\left(\frac{A r\left(u-u_{m f}\right)}{n_{o r i}}\right)^{0.4} \\
\text { (perforated plate) }\end{array}$} & \multirow[b]{2}{*}{$\begin{array}{l}D=0.3-1.3 \mathrm{~m}, d_{P}=60-450 \\
u_{m f}=0.005-0.2 ; u-u_{m f}=0.008 \\
-0.48\end{array}$} \\
\hline $\begin{array}{l}\text { (Horio and } \\
\text { Nonaka, } \\
1987)\end{array}$ & $\begin{array}{l}\left(\frac{\sqrt{d_{b}}-\sqrt{d_{b e}}}{\sqrt{d_{b 0}}-\sqrt{d_{b e}}}\right)^{1-\frac{\gamma_{m}}{\eta}}\left(\frac{\sqrt{d_{b}}-\sqrt{\vartheta}}{\sqrt{d_{b 0}}-\sqrt{\vartheta}}\right)^{1+\frac{\gamma_{m}}{\eta}} \\
=\exp \left(-\frac{0.3 h}{D}\right)\end{array}$ & & \\
\hline
\end{tabular}

The impact of the various correlations presented in Table B.1 on the reactor length-dependent bubble diameter is shown in Figure B.1. For this analysis a hypothetical reactor was used, consistent with the dimensions and velocities of the reactors studied (Table 1). The objective of Figure B.1 is to illustrate the variance of bubble diameter with respect to the correlation used.

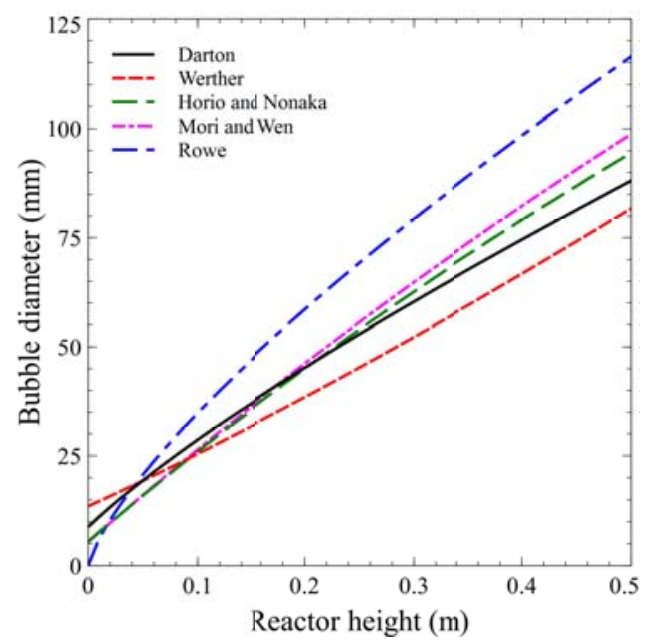

Figure B.1: Bubble diameter as estimated by different correlations for Geldart type B particles fluidization $\left(D=0.5 \mathrm{~m}, H=0.5 \mathrm{~m}, u_{m f}=0.03 \mathrm{~m} / \mathrm{s}, u_{s g}=0.15 \mathrm{~m} / \mathrm{s}\right)$. 
Table B.2: Commonly used mass transfer correlations for the 3-phase bubbling bed model

\begin{tabular}{ll}
\hline Reference & Mass transfer correlations \\
\hline (Kunii and Levenspiel, 1968a) & $K_{b c, j}=4.5\left(\frac{u_{m f}}{d_{b}}\right)+5.85\left(\frac{D_{j}^{0.5} g^{0.25}}{d_{b}^{\frac{5}{4}}}\right), K_{c e, j}=6.78\left(\frac{\varepsilon_{m f} D_{j} u_{b}}{d_{b}^{3}}\right)^{\frac{1}{2}}$ \\
(Sit and Grace, 1981) & $K_{b e, j}=0.4\left(\frac{u_{m f}}{d_{b}}\right)+5.85\left(\frac{D_{j}^{0.5} g^{0.25}}{d_{b}^{\frac{5}{4}}}\right)$ \\
\hline
\end{tabular}




\section{REFERENCES}

Abad, A., Adánez, J., García-Labiano, F., de Diego, L.F., Gayán, P., 2010. Modeling of the chemical-looping combustion of methane using a $\mathrm{Cu}$-based oxygen-carrier. Combust. Flame 157, 602-615.

Adánez, J., Abad, A., Garcia-Labiano, F., Gayan, P., De Diego, L.F., 2012. Progress in chemical-looping combustion and reforming technologies. Prog. Energy Combust. Sci. 38, $215-282$.

Adánez, J., García-Labiano, F., de Diego, L.F., Gayán, P., Celaya, J., Abad, A., 2006. NickelCopper Oxygen Carriers To Reach Zero $\mathrm{CO}$ and $\mathrm{H}_{2}$ Emissions in Chemical-Looping Combustion. Ind. Eng. Chem. Res. 45, 2617-2625.

Aspen, 2007. Aspen Technology: Physical Properties System.

Baskakov, A.P., 1985. Heat transfer in fluidized beds: Radiative heat transfer in fluidized beds, in: Davidson, J.F., Clift, R., Harrison, D. (Eds.), Fluidization. pp. 465-472.

Bi, H., Grace, J., 1995. Flow regime diagrams for gas-solid fluidization and upward transport. Int. J. Multiph. Flow 21, 1229 - 1236.

Bolhàr-Nordenkampf, J., Pröll, T., Kolbitsch, P., Hofbauer, H., 2009. Comprehensive modeling tool for chemical looping based processes. Chem. Eng. Technol. 32, 410-417.

Bollas, G.M., Vasalos, I.A., Lappas, A.A., 2007. Integrated FCC riser-regenerator dynamics studied in a fluid catalytic cracking pilot plant. Chem. Eng. Sci. 62, $1887-1904$.

Bollas, G.M., Vasalos, I.A., Lappas, A.A., Iatridis, D., 2002. Modeling Small-Diameter FCC Riser Reactors. A Hydrodynamic and Kinetic Approach. Ind. Eng. Chem. Res. 41, 5410 5419.

Botterill, J.S.M., 1975. Fluid-bed heat transfer. Academic Press, New york, New York.

Brahimi, D., Choi, J.-H., Youn, P.S., Jeon, Y.-W., Kim, S.D., Ryu, H.-J., 2012. Simulation on Operating Conditions of Chemical Looping Combustion of Methane in a Continuous Bubbling Fluidized-Bed Process. Energy \& Fuels 26, 1441-1448.

Brown, T.A., Dennis, J.S., Scott, S.A., Davidson, J.F., Hayhurst, A.N., 2010. Gasification and Chemical-Looping Combustion of a Lignite Char in a Fluidized Bed of Iron Oxide. Energy \& Fuels 24, 3034-3048. 
Cabello, A., Gayán, P., García-Labiano, F., de Diego, L.F., Abad, A., Izquierdo, M.T., Adánez, J., 2014. Relevance of the catalytic activity on the performance of a $\mathrm{NiO} / \mathrm{CaAl}_{2} \mathrm{O}_{4}$ oxygen carrier in a CLC process. Appl. Catal. B Environ. 147, 980-987.

Chandel, M.K., Hoteit, A., Delebarre, A., 2009. Experimental investigation of some metal oxides for chemical looping combustion in a fluidized bed reactor. Fuel 88, 898-908.

Choi, J., Youn, P., Brahimi, D., Jeon, Y., 2012. A model on chemical looping combustion of methane in a bubbling fluidized-bed process. Korean J. Chem. Eng. 29, 737-742.

Darton, R.C.C., 1977. Bubble growth due to coalescence in fluidized beds. Chem. Eng. Res. Des. $55,274-280$.

Davidson, J.F., Harrison, D., 1963. Fluidized Particles. Cambridge University Press, Cambridge.

De Diego, L.F., García-Labiano, F., Gayán, P., Celaya, J., Palacios, J.M., Adánez, J., 2007.

Operation of a 10kWth chemical-looping combustor during $200 \mathrm{~h}$ with a $\mathrm{CuO}-\mathrm{Al}_{2} \mathrm{O}_{3}$ oxygen carrier. Fuel 86, 1036-1045.

Deng, Z., Xiao, R., Jin, B., Song, Q., 2009. Numerical simulation of chemical looping combustion process with $\mathrm{CaSO}_{4}$ oxygen carrier. Int. J. Greenh. Gas Control 3, 368-375.

Dennis, J.S., Scott, S.A., 2010. In situ gasification of a lignite coal and $\mathrm{CO}_{2}$ separation using chemical looping with a Cu-based oxygen carrier. Fuel 89, 1623-1640.

Fan, L., Li, F., Ramkumar, S., 2008. Utilization of chemical looping strategy in coal gasification processes. Particuology 6, 131-142.

García-Labiano, F., de Diego, L.F., Adánez, J., Abad, A., Gayán, P., 2005. Temperature variations in the oxygen carrier particles during their reduction and oxidation in a chemicallooping combustion system. Chem. Eng. Sci. 60, 851-862.

Gascon, J., Tellez, C., Herguido, J., Jakobsen, H.A., Menendez, M., 2006. Modeling of fluidized bed reactors with two reaction zones. AIChE J. 52, 3911-3923.

Gayán, P., Dueso, C., Abad, A., Adánez, J., de Diego, L.F., García-Labiano, F., 2009. NiO/ $\mathrm{Al}_{2} \mathrm{O}_{3}$ oxygen carriers for chemical-looping combustion prepared by impregnation and depositionprecipitation methods. Fuel 88, 1016-1023.

Haider, A., Levenspiel, O., 1989. Drag coefficient and terminal velocity of spherical and nonspherical particles. Powder Technol. 58, 63-70.

Håkonsen, S.F., Blom, R., 2011. Chemical looping combustion in a rotating bed reactor--finding optimal process conditions for prototype reactor. Environ. Sci. Technol. 45, 9619-26. 
Han, L., Zhou, Z., Bollas, G.M., 2013. Heterogeneous modeling of chemical-looping combustion. Part 1: Reactor model. Chem. Eng. Sci. 104, 233-249.

Han, L., Zhou, Z., Bollas, G.M., 2014. Heterogeneous modeling of chemical-looping combustion. Part 2: Particle model. Chem. Eng. Sci. 113, 116-128.

Hatzantonis, H., Yiannoulakis, H., Yiagopoulos, A., Kiparissides, C., 2000. Recent developments in modeling gas-phase catalyzed olefin polymerization fluidized-bed reactors: The effect of bubble size variation on the reactor's performance. Chem. Eng. Sci. 55, 32373259.

Hoffmann, A.C., Janssen, L., Prins, J., 1993. Particle segregation in fluidised binary mixtures. Chem. Eng. Sci. 48, 1583-1592.

Horio, M., Nonaka, A., 1987. A generalized bubble diameter correlation for gas-solid fluidized beds. AIChE J. 33, $1865-1872$.

Hoteit, A., Chandel, M.K., Delebarre, A., 2009. Nickel- and copper-based oxygen carriers for chemical looping combustion. Chem. Eng. Technol.

Iliuta, I., Tahoces, R., Patience, G.S., Rifflart, S., Luck, F., 2010. Chemical-looping combustion process: Kinetics and mathematical modeling. AIChE J. 56, 1063-1079.

Jerndal, E., Mattisson, T., Lyngfelt, A., 2009a. Investigation of Different $\mathrm{NiO} / \mathrm{NiAl}_{2} \mathrm{O}_{4} \mathrm{Particles}$ as Oxygen Carriers for Chemical-Looping Combustion. Energy \& Fuels 94, 665-676.

Jerndal, E., Mattisson, T., Thijs, I., Snijkers, F., Lyngfelt, A., 2009b. NiO particles with Ca and $\mathrm{Mg}$ based additives produced by spray-drying as oxygen carriers for chemical-looping combustion. Energy Procedia 1, 479-486.

Jerndal, E., Mattisson, T., Thijs, I., Snijkers, F., Lyngfelt, A., 2010. Investigation of $\mathrm{NiO} / \mathrm{NiAl}_{2} \mathrm{O}_{4}$ oxygen carriers for chemical-looping combustion produced by spray-drying. Int. J. Greenh. Gas Control 4, 23-35.

Jin, Y., Wei, F., Wang, Y., 2003. Handbook of fluidization and fluid-particle systems, 1st ed, Handbook of fluidization and fluid-particle systems. Marcel Dekker, Inc., New York.

Johansson, M., Mattisson, T., Lyngfelt, A., 2006. Use of $\mathrm{NiO} / \mathrm{NiAl}_{2} \mathrm{O}_{4}$ Particles in a $10 \mathrm{~kW}$ Chemical-Looping Combustor. Ind. Eng. Chem. Res. 45, 5911-5919.

Jung, J., Gamwo, I.K., 2008. Multiphase CFD-based models for chemical looping combustion process: Fuel reactor modeling. Powder Technol. 183, 401-409. 
Kolbitsch, P., Pröll, T., Bolhàr-Nordenkampf, J., Hofbauer, H., Bolhar-Nordenkampf, J., 2009.

Design of a Chemical Looping Combustor using a Dual Circulating Fluidized Bed (DCFB) Reactor System. Chem. Eng. Technol. 32, 398-403.

Kolbitsch, P., Pröll, T., Hofbauer, H., 2009. Modeling of a 120kW chemical looping combustion reactor system using a Ni-based oxygen carrier. Chem. Eng. Sci. 64, 99-108.

Kqnno, H., Saito, S., 1969. Pneumatic conveying of solids through straight pipes. J. Chem. Eng. Japan 2, 211-217.

Kramp, M., Thon, A., Hartge, E.-U., Heinrich, S., Werther, J., 2011. The Role of Attrition and Solids Recovery in a Chemical Looping Combustion Process. Oil Gas Sci. Technol. 66, $277-290$.

Kronberger, B., Loffler, G., Hofbauer, H., 2003. Simulation of mass and energy balances of a chemical-looping combustion system, in: Proceedings of the International Conference in Energy for a Clean Environment.

Kronberger, B., Lyngfelt, A., Löffler, G., Hofbauer, H., 2005. Design and Fluid Dynamic Analysis of a Bench-Scale Combustion System with $\mathrm{CO}_{2}$ Separation-Chemical-Looping Combustion. Ind. Eng. Chem. Res. 44, 546-556.

Kunii, D., Levenspiel, O., 1968a. Bubbling bed model for kinetic processes in fluidized beds: Gas-Solid Mass and Heat Transfer and Catalytic Reactions. I EC Process Des. Dev. 7, 481492.

Kunii, D., Levenspiel, O., 1968b. Bubbling Bed Model. Model for Flow of Gas through a Fluidized Bed. Ind. Eng. Chem. Fundam. 7, 446-452.

Kunii, D., Levenspiel, O., 1969. Fluidization Engineering, 2nd ed. Butterworth-Heinemann.

Kunii, D., Levenspiel, O., 1990. Fluidized reactor models. 1. For bubbling beds of fine, intermediate, and large particles. 2. For the lean phase: freeboard and fast fluidization. Ind. Eng. Chem. Res. 29, 1226-1234.

Kunii, D., Levenspiel, O., 1997. Circulating fluidized-bed reactors. Chem. Eng. Sci. 52, 24712482.

Lawrence Livermore National Laboratory, 2012. SUNDIALS (SUite of Nonlinear and DIfferential/ALgebraic equation Solvers). 
Lyngfelt, A., Leckner, B., Mattisson, T., 2001. A fluidized-bed combustion process with inherent $\mathrm{CO}_{2}$ separation; application of chemical-looping combustion. Chem. Eng. Sci. 56, 31013113.

Lyngfelt, A., Thunman, H., 2005. Construction and $100 \mathrm{~h}$ of operational experience of a 10-kW chemical-looping combustor, in: Thomas, D. (Ed.), The $\mathrm{CO}_{2}$ Capture and Storage Project (CCP) for Carbon Dioxide Storage in Deep Geologic Formations For Climate Change Mitigation. Elsevier Science, London.

Mahalatkar, K., Kuhlman, J., Huckaby, E.D., O’Brien, T., 2011. CFD simulation of a chemicallooping fuel reactor utilizing solid fuel. Chem. Eng. Sci. 66, 3617-3627.

Mahalatkar, K.K., 2010. Ph.D. Thesis: Computational Fluid Dynamic Studies of Chemical Looping Combustion Systems. West Virginia University.

Marmo, L., Rovero, G., Baldi, G., 1999. Modelling of catalytic gas-solid fluidised bed reactors. Catal. today 52, 235-247.

Mattisson, T., Johansson, M., Jerndal, E., Lyngfelt, A., 2008. The reaction of $\mathrm{NiO} / \mathrm{NiAl}_{2} \mathrm{O}_{4}$ particles with alternating methane and oxygen. Can. J. Chem. Eng. 86, 756-767.

Mori, S., Wen, C., 1975. Estimation of bubble diameter in gaseous fluidized beds. AIChE J. 21, $109-115$.

Naimer, N.S., Chiba, T., Nienow, A.W., 1982. Parameter estimation for a solids mixing/segregation model for gas fluidised beds. Chem. Eng. Sci. 37, 1047-1057.

Noorman, S., Gallucci, F., van Sint Annaland, M., Kuipers, H.J.A.M., 2010. Experimental investigation of $\mathrm{a} \mathrm{CuO} / \mathrm{Al}_{2} \mathrm{O}_{3}$ oxygen carrier for chemical-looping combustion. Ind. Eng. Chem. Res. 49, 9720-9728.

Nordness, O., Zhou, Z., Bollas, G.M., 2014. Feasibility of Integration of Chemical Looping Combustion (CLC) in IGCC Systems: High Pressure CLC Experiments with $\mathrm{CH}_{4}$ and Syngas, in: AIChE Annual Meeting. Atlanta, GA.

Olazar, M., San José, M.J., Alvarez, S., Morales, A., Bilbao, J., 2004. Design of Conical Spouted Beds for the Handling of Low-Density Solids. Ind. Eng. Chem. Res. 43, 655-661.

Patience, G., Chaouki, J., Berruti, F., Wong, R., 1992. Scaling considerations for circulating fluidized bed risers. Powder Technol. 72, $31-37$. 
Peltola, P., Ritvanen, J., Tynjälä, T., Hyppänen, T., 2013a. Model-based evaluation of a chemical looping combustion plant for energy generation at a pre-commercial scale of $100 \mathrm{MW}_{\text {th }}$. Energy Convers. Manag. 76, 323-331.

Peltola, P., Ritvanen, J., Tynjälä, T., Pröll, T., Hyppänen, T., 2013b. One-dimensional modelling of chemical looping combustion in dual fluidized bed reactor system. Int. J. Greenh. Gas Control 16, 72-82.

Poling, B.E., Prausnitz, J.M., O’Connell, J.P., 2001. The properties of gases and liquids, Fifth. ed. McGRAW-HILL.

Process Systems Enterprise, gPROMS, www.psenterprise.com/gproms, 1997-2012, 2012.

Pröll, T., Kolbitsch, P., Bolhàr-Nordenkampf, J., Hofbauer, H., Bolhar-Nordenkampf, J., 2009. A novel dual circulating fluidized bed system for chemical looping processes. AIChE J. 55, $3255-3266$.

Rhodes, M., 2008. Introduction to Particle Technology, Chemical Engineering and Processing. John Wiley and Sons.

Rifflart, S., Hoteit, A., Yazdanpanah, M.M., Pelletant, W., Surla, K., 2011. Construction and operation of a $10 \mathrm{~kW} \mathrm{CLC}$ unit with circulation configuration enabling independent solid flow control. Energy Procedia 4, 333-340.

Rowe, P.N., 1976. Prediction of bubble size in a gas fluidised bed. Chem. Eng. Sci. 31, 285-288.

Rüdisüli, M., Schildhauer, T.J., Biollaz, S.M.A., van Ommen, J.R., 2012. Scale-up of bubbling fluidized bed reactors - A review. Powder Technol. 217, 21-38.

Rydén, M., 2008. Hydrogen production from fossil fuels with carbon dioxide capture, using chemical-looping technologies. Chalmers University of Technology.

Rydén, M., Johansson, M., Lyngfelt, A., Mattisson, T., 2009. NiO supported on $\mathrm{Mg}-\mathrm{ZrO}_{2}$ as oxygen carrier for chemical-looping combustion and chemical-looping reforming. Energy Environ. Sci. 2, 970 - 981.

Rydén, M., Lyngfelt, A., Mattisson, T., 2008. Chemical-Looping Combustion and ChemicalLooping Reforming in a Circulating Fluidized-Bed Reactor Using Ni-Based Oxygen Carriers. Energy \& Fuels 22, 2585-2597.

Ryu, H., Jin, G., Jo, S., Park, M., 2008. Natural gas combustion characteristics in a chemicallooping combustor with three different oxygen carrier particles. J. Chem. Eng. Japan 41, $716-720$. 
Ryu, H., Jin, G., Yi, C., 2004. Demonstration of inherent $\mathrm{CO}_{2}$ separation and no $\mathrm{NO}_{\mathrm{x}}$ emission in a $50 \mathrm{~kW}$ chemical-looping combustor: continuous reduction and oxidation experiment, in: Proceedings of the 7th International Conference on Greenhouse Gas Control Technologies. Vancouver.

Ryu, H.-J., Shun, D., Bae, D.-H.D.-H., Park, M.-H.M.-H., 2009. Syngas combustion characteristics of four oxygen carrier particles for chemical-looping combustion in a batch fluidized bed reactor. Korean J. Chem. Eng.

Sahir, A., Sohn, H., Lighty, J., 2013. A fluidized bed model of the fuel reactor for a Chemical Looping with Oxygen Uncoupling process, in: 8th US National Combustion Meeting.

Sane, S., Haynes Jr, H., Agarwal, P., 1996. An experimental and modelling investigation of gas mixing in bubbling fluidized beds. Chem. Eng. Sci. 51, 1133-1147.

Sedor, K.E., Hossain, M.M., de Lasa, H.I., 2008. Reactivity and stability of $\mathrm{Ni} / \mathrm{Al}_{2} \mathrm{O}_{3}$ oxygen carrier for chemical-looping combustion (CLC). Chem. Eng. Sci. 63, 2994-3007.

Shiau, C.C.-Y., Lin, C.C.-J., 1993. An improved bubble assemblage model for fluidized-bed catalytic reactors. Chem. Eng. Sci.

Shuai, W., Yunchao, Y., Huilin, L., Jiaxing, W., Pengfei, X., Guodong, L., 2011. Hydrodynamic simulation of fuel-reactor in chemical looping combustion process. Chem. Eng. Res. Des. $89,1501-1510$.

Sit, S.P., Grace, J.R., 1981. Effect of bubble interaction on interphase mass transfer in gas fluidized beds. Chem. Eng. Sci. 36, 327-335.

Tabis, B., Essekkat, A., 1992. Three-phase multi-compartment model for fluidized-bed catalytic reactors: autothermicity and multiplicity of steady states. Chem. Eng. Sci. 47, 407-419.

The Mathworks Inc., Matlab, 2013.

Wang, S., Lu, H., Li, D., Tang, Y., 2013. Simulation of the Chemical Looping Reforming Process in the Fuel Reactor with a Bubble-Based Energy Minimization Multiscale Model. Energy \& Fuels 27, 5008-5015.

Wang, S., Wang, G., Jiang, F., Luo, M., Li, H., 2010. Chemical looping combustion of coke oven gas by using $\mathrm{Fe}_{2} \mathrm{O}_{3} / \mathrm{CuO}$ with $\mathrm{MgAl}_{2} \mathrm{O}_{4}$ as oxygen carrier. Energy Environ. Sci. 3, 1353. 
Wang, S., Yang, Y., Lu, H., Xu, P., Sun, L., 2012. Computational Fluid Dynamic Simulation Based Cluster Structures-Dependent Drag Coefficient Model in Dual Circulating Fluidized Beds of Chemical Looping Combustion. Ind. Eng. Chem. Res. 51, 1396-1412.

Werther, J., 1976. Convective solids transport in large diameter gas fluidized beds. Powder Technol. 15, 155-167.

Werther, J., Reppenhagen, J., 1999. Catalyst attrition in fluidized-bed systems. AIChE J. 45, 2001-2010.

Werther, J., Reppenhagen, J., 2003. Attriton, in: Yang, W.-C. (Ed.), Handbook of Fluidization and Fluid-Particle Systems. Marcel Dekker, Inc., New York.

Werther, J., Xi, W., 1993. Jet attrition of catalyst particles in gas fluidized beds. Powder Technol.

Xavier, A.M., Davidson, J.F., 1985. Heat Transfer in Fluidized Beds: Convective Heat Transfer in Fluidized Beds, in: Davidson, J.F., Clift, R., Harrison, D. (Eds.), Fluidization. pp. 437464.

Xu, M., Ellis, N., Ryu, H., Lim, C., 2007. Modeling of an interconnected fluidized bed reactor for chemical looping combustion. 2007 ECI Conf. 12th Int. Conf. Fluid. - New Horizons Fluid. Eng.

Yazdanpanah, M.M., 2011. Investigation of a chemical looping combustion (CLC) with gas feed. Université Henri Poincaré.

Yazdanpanah, M.M., Forret, A., Gauthier, T., Delebarre, A., 2014. Modeling of $\mathrm{CH}_{4}$ combustion with $\mathrm{NiO} / \mathrm{NiAl}_{2} \mathrm{O}_{4}$ in a $10 \mathrm{~kW}_{\text {th }}$ CLC pilot plant. Appl. Energy $113,1933-1944$.

Zhao, Z., Chen, T., Ghoniem, A.F., 2013. Rotary Bed Reactor for Chemical-Looping Combustion with Carbon Capture. Part 1: Reactor Design and Model Development. Energy \& Fuels 27, 327-343.

Zhou, Z., Han, L., Bollas, G.M., 2013. Model-based analysis of bench-scale fixed-bed units for chemical-looping combustion. Chem. Eng. J. 233, 331-348.

Zhou, Z., Han, L., Bollas, G.M., 2014a. Overview of Chemical-Looping Reduction in Fixed Bed and Fluidized Bed Reactors Focused on Oxygen Carrier Utilization and Reactor Efficiency. Aerosol Air Qual. Res. 14, 559-571.

Zhou, Z., Han, L., Bollas, G.M., 2014b. Kinetics of $\mathrm{NiO}$ reduction by $\mathrm{H}_{2}$ and $\mathrm{Ni}$ oxidation at conditions relevant to chemical-looping combustion and reforming. Int. J. Hydrogen Energy $39,8535-8556$. 
Zhou, Z., Han, L., Nordness, O., Bollas, G.M., 2015. Continuous regime of chemical looping combustion (CLC) and chemical-looping with oxygen uncoupling (CLOU) reactivity of $\mathrm{CuO}$ oxygen carriers. Appl. Catal. B Environ. 166-167, 132-144.

Zhou, Z., Nordness, O., Han, L., Bollas, G.M., 2014c. Continuous Regime of CLC/CLOU Reactivity and Its Impact on the Dynamic and Steady State Performance of $\mathrm{Cu}_{\mathrm{x}} \mathrm{O}_{\mathrm{y}}$ Oxygen Carriers, in: AIChE Annual Meeting. Atlanta, GA. 

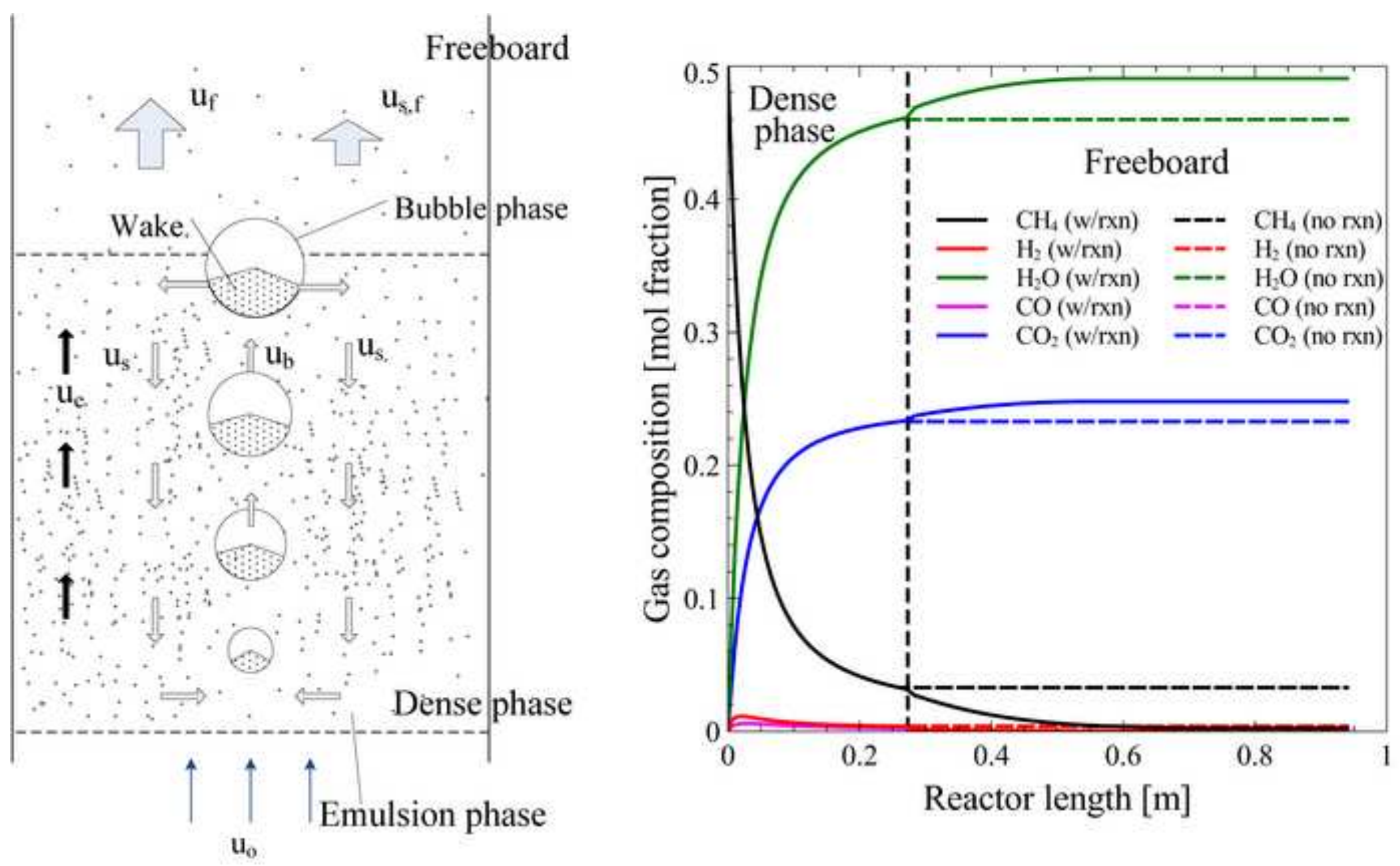